\title{
Technical Note: In-situ derivatization thermal desorption GC-TOFMS for direct analysis of particle-bound non-polar and polar organic species
}

\author{
J. Orasche ${ }^{1,2,3}$, J. Schnelle-Kreis ${ }^{2}$, G. Abbaszade ${ }^{2}$, and R. Zimmermann ${ }^{2,3}$ \\ ${ }^{1}$ Department of Sedimentology \& Environmental Geology, Georg-August-University, Göttingen, Germany \\ ${ }^{2}$ Joint Mass Spectrometry Centre - Cooperation Group “Comprehensive Molecular Analytics”, Helmholtz Zentrum \\ München, Neuherberg, Germany \\ ${ }^{3}$ Joint Mass Spectrometry Centre - Institute of Chemistry, Division of Analytical and Technical Chemistry, University of \\ Rostock, Rostock, Germany
}

Received: 21 April 2011 - Published in Atmos. Chem. Phys. Discuss.: 19 May 2011

Revised: 15 August 2011 - Accepted: 29 August 2011 - Published: 2 September 2011

\begin{abstract}
An in-situ derivatization thermal desorption method followed by gas chromatography and time-of-flight mass spectrometry (IDTD-GC-TOFMS) was developed for determination of polar organic compounds together with non-polar compounds in one measurement. Hydroxyl and carboxyl groups of compounds such as anhydrous sugars, alcohols and phenols, fatty acids and resin acids are targets of the derivatization procedure. Derivatization is based on silylation with N-Methyl-N-trimethylsilyltrifluoroacetamide (MSTFA) during the step of thermal desorption. The high temperature of $300^{\circ} \mathrm{C}$ during desorption is utilized for the in-situ derivatization on the collection substrate (quartz fibre filters) accelerating the reaction rate. Thereby, the analysis time is as short as without derivatization. At first the filter surface is dampened with derivatization reagent before insertion of the sample into the thermal desorption unit. To ensure ongoing derivatization during thermal desorption the carrier gas is enriched with MSTFA until the desorption procedure is finished. The precisions of all studied analytes were below $17 \%$ within a calibration range from $22 \mathrm{pg}$ (abietic acid) up to $342 \mathrm{ng}$ (levoglucosan). Limits of quantification (LOQ) for polycyclic aromatic hydrocarbons (PAH) were between $1 \mathrm{pg}$ (fluoranthene) and $8 \mathrm{pg}$ (indeno[1,2,3-cd]pyrene), for resin acids 37-102 pg and for studied phenols 4-144 pg. LOQ for levoglucosan was $17 \mathrm{pg}$.
\end{abstract}

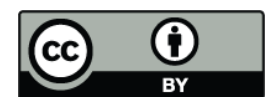

Correspondence to: J. Schnelle-Kreis (juergen.schnelle@helmholtz-muenchen.de)

\section{Introduction}

During the last decade direct thermal desorption (DTD) (someone like to prefer the term "extraction" which implies the removal of analytes from a native matrix) methods were developed for quantification of semi volatile organic compounds (SVOC) adsorbed on ambient particulate matter (PM) (Falkovich, 2001; Waterman, 2000). The advantage of DTD is the reduction of analytes losses and memory effects by desorption of the sample within the GC injector. Desorption inside of the injector with a short way to the separation column prevents cold spots. Combined with the possibility of using a fresh glass liner for every sample memory effects are avoided and analytes losses are minimized. In recent years an increasing number of samples had to be analysed for studying aerosol composition. A growing variety of organic compounds becomes more and more important for source apportionment (Dutton, 2009; Sklorz, 2007; Vedal, 2009), aerosol ageing studies and investigations on characteristics of particles responsible for climatic effects (Donahue, 2009). Therefore direct thermal desorption hyphenated with GC-MS can be a useful tool to deal daily sampling on long time series (Schnelle-Kreis, 2005a) or with high time resolution. Some research groups developed methods for direct thermal desorption for analysis of organic aerosol compounds in the past (Bates, 2008; Ding, 2009; Falkovich, 2001; Gil-Moltó, 2009; Hays, 2003; Ho, 2008; Schnelle-Kreis, 2005b; van Drooge, 2009). Extensive reviews about thermal methods for chemical characterization of carbonaceous aerosols were published by Hays and Lavrich (2007) and Chow et al. (2007).

Published by Copernicus Publications on behalf of the European Geosciences Union. 
A recent development in thermal desorption techniques is the Thermal Desorption Aerosol GC-MS (TAG) (Lambe, 2010; Williams, 2006, 2010). Particles with a cut-point of $\mathrm{PM}_{2}$ are collected by humidifying and impaction into a thermal desorption cell. After a defined sampling time the organic matter is transferred to the gas chromatograph by thermal desorption. A high time resolution of one hour per sample and the chromatographic separation are the advantages of the TAG system.

Another development for thermal desorption of precipitated particulate matter is the methylation by tetramethylammonium hydroxide (TMAH) and its derivatives (Beiner, 2009; Fabbri et al., 2002) for quantification of organic acids. The applicability for other polar compounds is currently under investigation. Furthermore an in-situ methylation of carboxylic acids by treatment of filter samples with diazomethane was introduced by Sheesley et al. (2010).

Polar organic substances are playing a major role in characterization of diverse atmospheric processes and also during formation of aerosols. The main organic combustion product of wood is the anhydrous sugar levoglucosan as a decomposition product of cellulose. This compound as well as its homologues mannosan and galactosan, decomposition products of hemi cellulose, are ubiquitous constituents of the atmosphere (Simoneit, 1999, 2004). Further wood combustion products originating from lignin breakdown or colophony can be observed. Most of them are of polar nature (Bari, 2009; Fine, 2001, 2002 and 2004; Nolte, 2001). Another main source of polar organic compounds in the atmosphere are biogenic emissions. Not only sugars from plants, fungi and bacteria can be observed (Medeiros et al., 2006; Medeiros and Simoneit, 2007), but also huge amounts of unsaturated hydrocarbons are continuously evaporated by vegetation (Guenther et al., 1995; Kourtchev et al., 2005). Once organic substances are released to the atmosphere as gas or particle-bound they are exposed to UV radiation, radicals and oxidants. Depending on particle properties (e.g. pH value, possible reaction agents) reaction mechanisms and reaction rates are affected. In ageing studies these facts are taken into account to investigate the formation of secondary organic aerosol (Hallquist et al., 2009). All of these reactions steadily increase the polarity of the reactants. Hence it is essential to implement an appropriate analytical method for observation of the polar organic tracers described and their behaviour immediately after combustion processes or in the atmosphere (Edney et al., 2003; Oliveira et al., 2007), e.g. supported by chamber experiments (Chiappini et al., 2006; Edney, 2005). Investigation of polar organic compounds is of great scientific interest due to their effect on particulate properties impacting climate processes. An increasing oxidation rate leads to acidification and growing of particles. The ongoing ageing is responsible for transformation of particles to cloud condensation nuclei (CCN).

In this work an in-situ derivatization thermal desorption method followed by gas chromatography and time-of-flight mass spectrometry (IDTD-GC-TOFMS) is introduced combining short sampling time, powerful chromatographic separation and determination of polar organic and non-polar organic substances in one measurement. Like DTD IDTD is a less time consumption method with relatively low costs compared to solvent extracting methods followed either by HPLC or GC. Moreover the possibility of in-situ-derivatization is something like a front-end for already installed DTD systems. Although it is not necessary to derivatize components when working with HPLC it is not necessary to pretreat samples in any extensive way when using IDTD. A very interesting technique without derivatization procedure is a fast two-dimensional gas chromatography method that uses heart-cutting and thermal extraction (TE-GC-GC-MS). Yet it seems to be established for anhydrous sugars, nalkanoic acids, substituted phenols, and nitrogen-bearing heterocyclics (Ma et al., 2008 and 2010). The combination of a non-polar separation phase with a polar one provides quantifiable sharp peaks in the chromatograms. Nevertheless compared to GC systems with highly polar separation columns IDTD is a more sensitive way to transfer delicate molecules from injector to column.

For inter comparison NIST Standard Reference Material Urban Dust SRM 1649a (National Institute of Standards and Technology, USA) was employed to validate the method for analysis of polycyclic hydrocarbons (Bates, 2008; Falkovich, 2001; Gil-Moltó, 2009; Ho, 2008; van Drooge, 2009; Waterman, 2000, 2001). Levoglucosan, mannosan and galactosan were determined in the standard reference material and compared to results already published by Kuo et al. (2008), Larsen et al. (2006) and Louchouarn et al. (2009). Comparison of different methods for analysis of ambient aerosol samples was carried out, too, (Ho, 2004, 2008; Ma, 2010; van Drooge, 2009) concerning polar substances, polycyclic aromatic hydrocarbons (PAH) and oxidized polycyclic hydrocarbons (o-PAH). PAH and even more o-PAH are delicate analytes due to generate artefacts during sampling, sample preparation and analysis (Liu, 2006). Therefore, analysis methods for these substance classes have to be validated properly. The direct thermal desorption (DTD) method presented here as a reference method was already introduced in former papers by Schnelle-Kreis et al. (2005a, b, 2007). Here the accuracy of this method is demonstrated briefly.

\section{Experimental}

\subsection{Sampling of ambient aerosol}

Prior to sampling quartz fibre filters were baked for at least eight hours at $550^{\circ} \mathrm{C}$ to remove all organic matter. The sampler was located at the aerosol characterization site of the Helmholtz Zentrum München at the University of Applied Sciences, Augsburg, next to the inner city of Augsburg, 
Germany (UAS, urban background). Samples were taken from 1 March 2010 to 14 March 2010.

For chemical analysis $\mathrm{PM}_{2.5}$ samples were collected with a low volume sequential sampler (Partisol-Plus Model 2025, Rupprecht \& Patashnick, NY, USA) on quartz fibre filters (T293, Munktell, Grycksbo, Sweden) at a flow rate of $16.71 \mathrm{~min}^{-1}$. Sampling time was 24 hours, thus airborne particulate matter of $24 \mathrm{~m}^{3}$ of air was collected on each filter. The samples were stored in glass containers at $-18^{\circ} \mathrm{C}$ until analysis. Filters for solvent extraction were extracted directly after sampling.

\subsection{Basics of In-situ Derivatization and Thermal Desorption (IDTD)}

The enhanced IDTD method involves the option to quantify polar constituents of organic particulate matter. The method presented allows derivatization of the polar organic fraction of filter samples in-situ on the filter during thermal desorption. Derivatization and desorption of polar organic compounds occurs directly from particulate matter on the filters. The advantages of a direct thermal desorption system employed for this study are: (1) direct placement of samples in the GC liner, so called in-injector thermal desorption avoiding sample transfer lines frequently causing cold spots, (2) the possibility of automatic liner exchange, (3) rapid heating rates of the injector and (4) replacement of the GC liner for every sample.

The derivatization procedure consists of two steps and is fully automated with an applicable sampling robot. The first step is the addition of liquid derivatization reagent N-Methyl$\mathrm{N}$-trimethylsilyl-trifluoroacetamide (MSTFA) by a syringe for complete moistening of filter and particulate matter. The second step is very important for quantitative silylation of polar organic compounds by MSTFA. The carrier gas is saturated with derivatization reagent by switching to a second pathway leading over a cartridge filled with MSTFA during the thermal desorption process (Fig. 1). The high temperature of $300^{\circ} \mathrm{C}$ during desorption increases derivatization rate sufficiently without additional catalyst.

The in-situ derivatization thermal desorption GC-TOFMS (IDTD-GC-TOFMS) was employed for the main anhydrous sugars levoglucosan, galactosan and mannosan occurring in ambient aerosol and further highly polar organic compounds like resin acids and lignin combustion products. Analysis of levoglucosan is possible by many different methods published in a variety of papers. An overview of detection and quantification of levoglucosan in atmospheric aerosols is given by the review of Schkolnik and Rudich (Schkolnik, 2006). As a conclusion of these studies we can find that the choice of solvent or solvent mixture is most crucial for methods using solvent extraction (Louchouarn, 2009). The polarity of the extraction solvent constitutes a limiting factor for the extraction yield of levoglucosan. To determine all substance classes being of interest for studying ambient

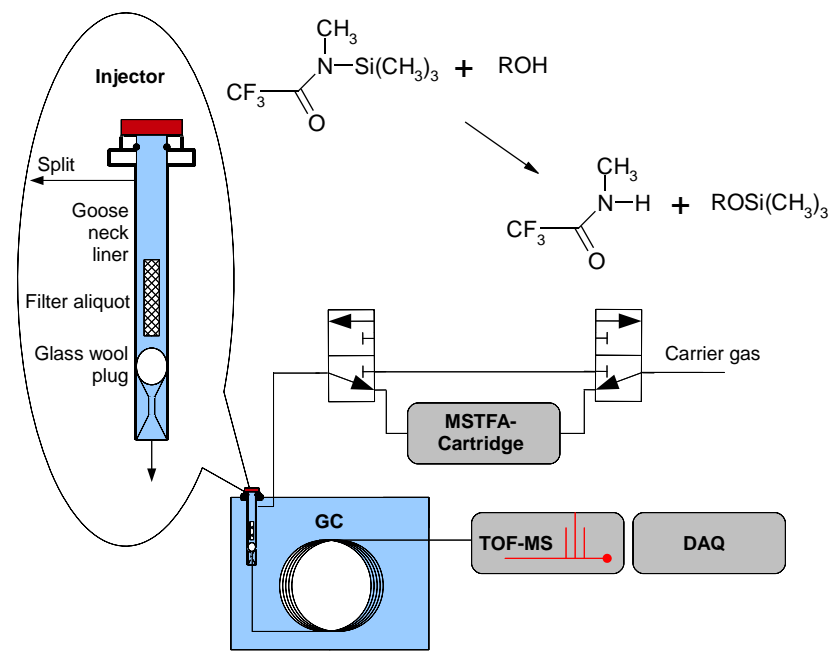

Fig. 1. In-situ derivatization and thermal desorption unit. The cartridge with an glas insert filled with MSTFA is localized directly before the thermal desorption unit. On the top of the figure: chemical equation of the silylation reaction of polar organic compounds with MSTFA.

aerosol it may be necessary to extract different polar fractions by different solvents. The advantage of the described in-situ derivatization thermal desorption method is minimization of the working steps, avoiding handling with different solvent mixtures and making even highly polar substances ascertainable. An overview of the compound classes analysed is shown in Fig. 2 in terms of single ion chromatograms.

\subsection{Sample preparation, In-situ Derivatization and Thermal Desorption}

For analysis of particulate matter collected the filters were cut by a special tool into filter aliquots which were stripes of the dimension $13.5 \mathrm{~mm} \times 2 \mathrm{~mm}$. One filter stripe (sample aliquot of $0.55 \mathrm{~m}^{3}$ of sampled air) was spiked with two internal standard mixtures (isotope-labelled reference compounds) for quantification. The first (non polar) internal standard consisted of fifteen deuterated PAH, two deuterated oPAH and four deuterated alkanes. $\mathrm{D}_{8}-9,10$-anthracenedione and $\mathrm{D}_{10}$-benz[a]anthracene-7,12-dione were synthesized in our laboratory (Liu, 2006) (see Table S1 in the supplementary information for detailed description and concentrations). The second (polar) internal standard mixture contained ${ }^{13} \mathrm{C}_{6}$ levoglucosan (Omicron Biochemicals, USA), ${ }^{13} \mathrm{C}_{6}$-vanillin (Larodan, Sweden) and $\mathrm{D}_{31}$-palmitic acid (CIL, USA). Samples were placed into goose-neck glass-liners for thermal desorption which were sealed with PTFE caps. For each sample a freshly deactivated GC liner was used. Deactivation was done by annealing the liners at $550^{\circ} \mathrm{C}$ for at least twelve hours followed by a derivatization treatment of the glass surface with chlorotrimethylsilan (TMCS, Merck, Germany) for further twelve hours. A glass wool plug above 
a)

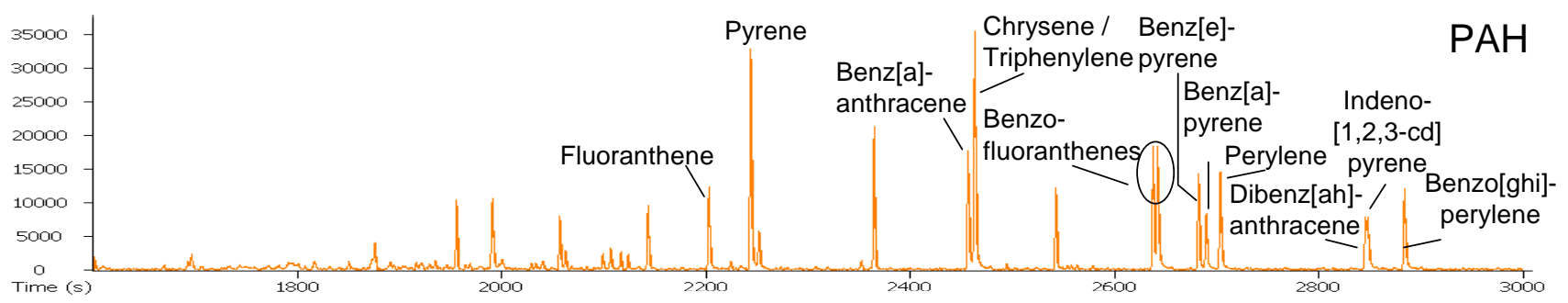

b)

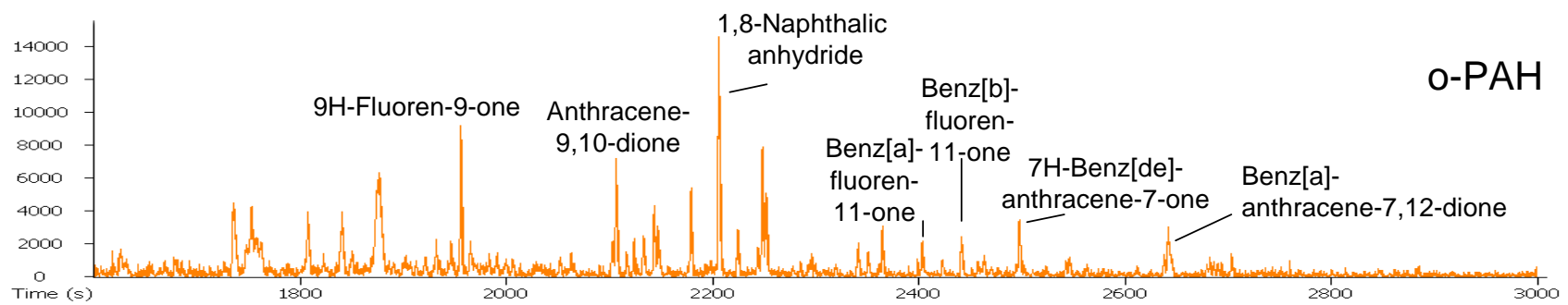

c)

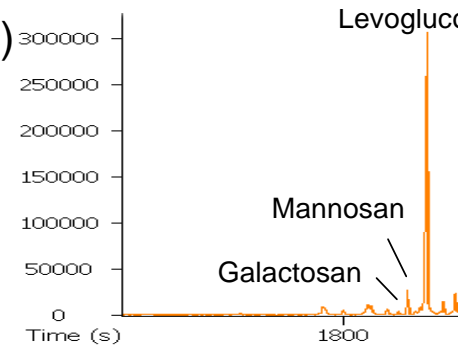

d)

Dehydroabietic acid
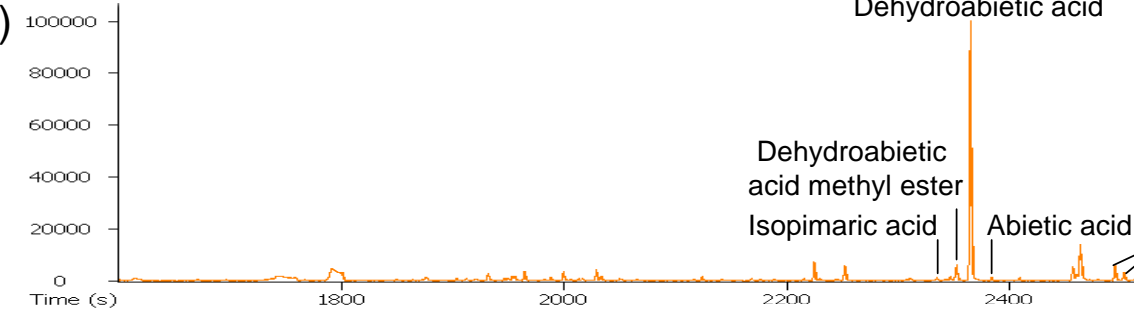

Anhydrous sugars

e)

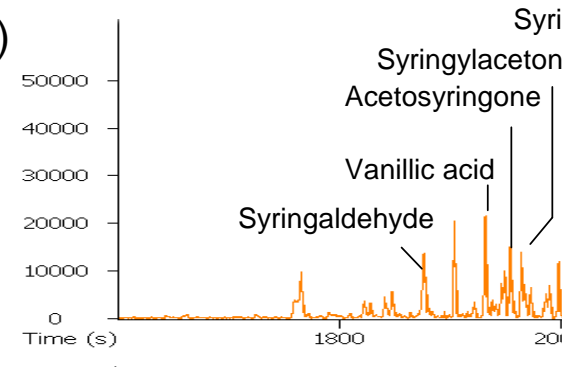

Syringic acid

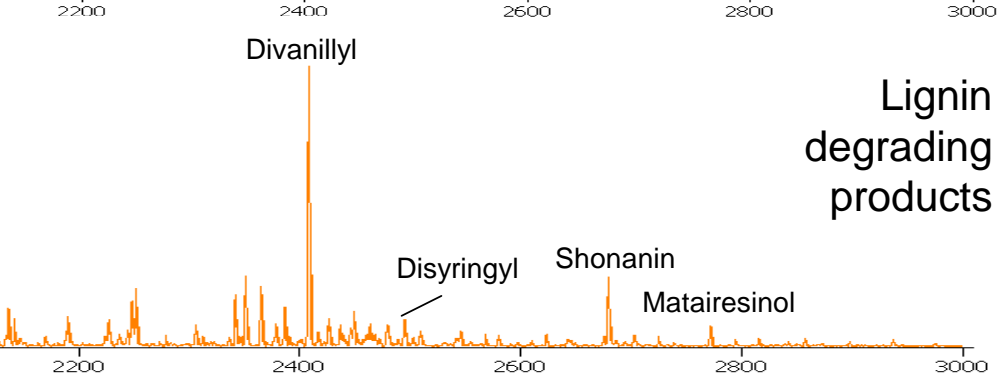

7-Oxodehydroabietic acid /

Resin acids

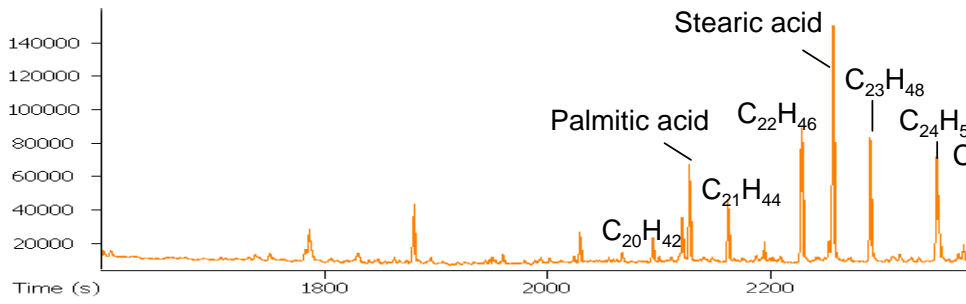

Divanillyl

f)

Fig. 2. Multiple ion chromatograms reflecting differ (a) UAS (urban background): (a) polycyclic aromatic hydrocarbons $(\mathrm{PAH})(\mathrm{m} / \mathrm{z}, 178+202+228+252+276+278),(\mathbf{b})$ oxidized PAH (o-PAH) $(\mathrm{m} / \mathrm{z}, 126+158+180+196+230+258)$, (c) anhydrous sugars $(\mathrm{m} / \mathrm{z}, 204+217),(\mathbf{d})$ resin acids $(\mathrm{m} / \mathrm{z}, 239+241+253),(\mathbf{e})$ lignin degradation products $(\mathrm{m} / \mathrm{z}, 194+209+224+238+279+297+327)$, (f) alkanes and fatty acids $(\mathrm{m} / \mathrm{z}, 57+117)$. 
the goose-neck prevented particles from the filter to enter the capillary column.

For analysis of the NIST Standard Reference Material Urban Dust 1649a portions of $0.06 \mathrm{mg}$ were thermally desorbed. Due to the small amount required the urban dust was diluted and homogenized first with an inert matrix of sodium sulphate (w/w, 1/1000) which was annealed and ground before. The GC injection liners were loaded with $60 \mathrm{mg}$ of this mixture. Isotope-labelled standards were added to this mixture. The liners were also sealed with PTFE caps until analysis.

Further treatments were carried out by a sampling robot (Focus, Atas GL, Netherlands). Prior to analysis liners were opened and $10 \mu \mathrm{l}$ MSTFA (Macherey-Nagel, Germany) was added in each liner to moisten the sample surface. Liners were placed into a direct (in-injector) thermal desorption unit (Optic 3, Atas GL, Netherlands) mounted on the gas chromatograph. The sampling robot exchanged the complete GC liners placed in the injector which was automatically closed and opened by a liner exchanging unit (Linex, Atas GL, Netherlands). After liners were placed into the cold injector $\left(60^{\circ} \mathrm{C}\right)$ a steady flow of carrier gas (helium) removed the air. During this venting step of 60 seconds carrier gas flow was $0.7 \mathrm{ml} \mathrm{min}^{-1}$, split flow was $50 \mathrm{ml} \mathrm{min}^{-1}$. After $180 \mathrm{~s}$ carrier gas flow was increased split less to $4 \mathrm{ml} \mathrm{min}^{-1}$. The carrier gas was lead to a bypass with a cartridge filled with MSTFA before entering the injector. Immediately after the flow reached the desired value the bypass was opened via two 3-port/2-way solenoid valves being controlled by the Optic software and hardware unit (Atas GL, Netherlands). The injector was heated up to $300^{\circ} \mathrm{C}$ with a heating rate of $2{ }^{\circ} \mathrm{C} \mathrm{s}^{-1}$ directly after bypass was opened. During $16 \mathrm{~min}$ of reaction and desorption time the carrier gas was continuously saturated with derivatization reagent (Fig. 1). Subsequently the bypass was closed and the column flow was set to $0.71 \mathrm{~min}^{-1}$ with a split flow of $501 \mathrm{~min}^{-1}$ directly after thermal desorption was finished.

\subsection{Gas chromatography and time-of-flight mass spectrometry}

Desorbed molecules were focused at $70{ }^{\circ} \mathrm{C}$ on the head of the capillary column, BPX5, $25 \mathrm{~m}, 0.22 \mathrm{~mm}$ ID, $0.25 \mu \mathrm{m}$ film (SGE, Australia) which was installed in an Agilent 6890 gas chromatograph (Agilent, USA). The thermal desorption step was followed by heating up the GC oven to $130^{\circ} \mathrm{C}$ with a rate of $80^{\circ} \mathrm{C} \mathrm{min}-1$. Then the rate was lowered to $8{ }^{\circ} \mathrm{C}$ $\min ^{-1}$ until a temperature of $330^{\circ} \mathrm{C}$ was reached followed by an isothermal time of $30 \mathrm{~min}$.

Identification and quantification of target compounds were carried out on a Pegasus III TOFMS using Chroma TOF software package (LECO, USA) being capable of peak deconvolution. The data acquisition range was $\mathrm{m} / \mathrm{z} 35$ to 500 with an acquisition frequency of 25 spectra per second which is necessary for reliable peak deconvolution.
Analytes which were not available as standard in analytical grade were identified by their mass spectra and the retention time index. In those cases quantification was achieved with an adequate surrogate standard on semi quantitative basis. Surrogates are specified in Table S1.

\subsection{Calibration of thermal desorption}

The calibration of the thermal desorption method was carried out applying standard addition to reference filters (PM samples). The standard addition method was used here to minimize the matrix effects. The reference samples were collected at the aerosol characterization site in Augsburg, Germany, to obtain references with similar matrix to other field samples. These filters were spiked with internal standard and derivatization standard respectively. Standard mixtures with native organic compounds were added to the reference filters in different concentration levels (for calibration ranges see Table 1). Further filter treatment was identical to that described in section 2.3.

\subsection{Direct Thermal Desorption (DTD)}

DTD was described in detail elsewhere (Schnelle-Kreis, 2005a, b, 2007). The pre-treatment of filters and liners for DTD was identical as described above without adding the isotope-labelled standard mixture of polar compounds. The used instrument is identical to that used for IDTD. The vent time before thermal desorption was shorter (one minute) than in IDTD method and the carrier gas was not treated with derivatization reagent during thermal desorption process. In that case the valves stayed closed and no MSTFA was added.

\subsection{Solvent extraction of non-polar compounds}

The method for solvent extraction of non-polar compounds was described elsewhere (Liu, 2006; Sklorz, 2007). Extraction was carried out utilizing soxhlet extraction with dichloromethane as solvent. Therefore, filters or a mixture of SRM 1649a and sodium sulphate were placed in fritted soxhlet sleeves made of glass. Soxhlet extraction time was $16 \mathrm{~h}$ with at least six cycles per hour. Extracts were dried over pre-baked sodium sulphate and filtrated to remove filter residues. Extracts were concentrated to $1 \mathrm{ml}$ and additionally cleaned up and fractionated on a liquid chromatography column packed with silica (Promochem, Germany) deactivated with three percent of water. First alkanes were eluted from the column by a solvent mixture of hexane/dichloromethane $(9: 1, v / v)$. In the second and third fraction PAH and o-PAH were eluted after each other by hexane/dichloromethane (1:1, $\mathrm{v} / \mathrm{v})$ and dichloromethane/methanol $(19: 1, \mathrm{v} / \mathrm{v})$ respectively (all solvents: Merck, Germany). The mixtures were concentrated to adjust the concentrations of the analytes to the same range as applied for DTD (one injection equates to $1 \mathrm{~m}^{3}$ of sampled air). Samples were analysed by GC-HRMS. 
Table 1. Validation parameters obtained from the calibration curves of IDTD-GC-TOF MS. Calibration range means lowest and highest standard concentrations used for the calibration curve; $a=$ interception, $b=$ slope (area ratio/mass ratio). The limit of quantification (LOQ) of the method is defined as the minimum amount of substance that is according to the minimum reliable signal plus nine times (three times for LOD) the standard deviation of this underground signal. The complementary information of SE-GC-TOFMS can be found in the supplementary information (Table S2).

\begin{tabular}{|c|c|c|c|c|c|c|}
\hline Analyte & Calibration range $[\mathrm{ng}]$ & $a$ & $b$ & $R^{2}$ & Precision & LOQ per sample [ng] \\
\hline Phenanthrene & $0.790-39.5$ & 0.044 & 1.148 & 0.999 & $3 \%$ & 0.003 \\
\hline Anthracene & $0.212-10.6$ & -0.132 & 1.789 & 0.983 & $15 \%$ & 0.003 \\
\hline Fluoranthene & $0.283-14.1$ & 0.050 & 1.403 & 0.998 & $5 \%$ & 0.001 \\
\hline Pyrene & $0.392-19.6$ & 0.007 & 1.315 & 1.000 & $1 \%$ & 0.005 \\
\hline Benzo[a]anthracene & $0.290-14.5$ & -0.217 & 1.871 & 0.997 & $7 \%$ & 0.003 \\
\hline Chrysene & $0.277-13.8$ & 0.018 & 0.534 & 0.998 & $5 \%$ & 0.004 \\
\hline sum Benzofluoranthenes & $0.098-4.89$ & 0.017 & 0.805 & 1.000 & $2 \%$ & 0.002 \\
\hline Benzo[e]pyrene & $0.134-6.71$ & -0.021 & 1.523 & 1.000 & $2 \%$ & 0.003 \\
\hline Benzo[a]pyrene & $0.130-6.49$ & -0.010 & 1.384 & 0.999 & $4 \%$ & 0.005 \\
\hline Perylene & $0.070-3.52$ & -0.092 & 1.510 & 0.996 & $7 \%$ & 0.004 \\
\hline Indeno[1,2,3-cd]pyrene & $0.069-3.44$ & 0.139 & 0.850 & 0.996 & $6 \%$ & 0.008 \\
\hline Dibenzo[ah]anthracene & $0.072-3.60$ & 0.859 & 1.288 & 0.986 & $7 \%$ & 0.006 \\
\hline Benzo[ghi]perylene & $0.073-3.63$ & 0.030 & 1.833 & 0.999 & $3 \%$ & 0.004 \\
\hline Coronene & $0.072-3.60$ & -0.065 & 1.175 & 0.996 & $7 \%$ & 0.002 \\
\hline 9H-Fluoren-9-one & $0.362-18.1$ & -0.100 & 0.826 & 0.977 & $17 \%$ & 0.005 \\
\hline 9,10-Anthracenedione & $0.280-14.0$ & -0.012 & 0.485 & 1.000 & $2 \%$ & 0.028 \\
\hline 1,8-Naphthalic anhydride & $0.414-20.7$ & 0.215 & 0.613 & 0.993 & $9 \%$ & 0.026 \\
\hline Cyclopenta[def]phenanthrenone & $0.075-3.74$ & -0.058 & 0.479 & 0.987 & $17 \%$ & 0.012 \\
\hline 11H-Benzo[a]fluoren-11-one & $0.081-4.06$ & 0.016 & 0.157 & 0.988 & $12 \%$ & 0.033 \\
\hline 11H-Benzo[b]fluoren-11-one & $0.079-3.93$ & 0.010 & 0.638 & 0.990 & $11 \%$ & 0.008 \\
\hline Benzo[a]anthracene-7,12-dione & $0.37-18.5$ & -0.704 & 3.026 & 0.995 & $9 \%$ & 0.229 \\
\hline Malic acid & $0.976-97.6$ & 0.143 & 0.033 & 0.931 & $10 \%$ & 1.59 \\
\hline Vanillin & $0.057-5.67$ & -0.016 & 1.077 & 0.985 & $10 \%$ & 0.144 \\
\hline Galactosan & $0.221-22.1$ & 0.046 & 1.288 & 0.992 & $11 \%$ & 0.048 \\
\hline Mannosan & $1.05-105$ & 0.101 & 0.575 & 0.981 & $14 \%$ & 0.033 \\
\hline Levoglucosan & $3.42-342$ & 0.405 & 0.495 & 0.994 & $6 \%$ & 0.017 \\
\hline Phthalic acid & $0.604-60.4$ & -0.003 & 0.239 & 0.983 & $14 \%$ & 0.054 \\
\hline Vanillic acid methyl ester & $0.054-5.44$ & -0.040 & 2.539 & 0.986 & $17 \%$ & 0.067 \\
\hline Vanillic acid & $0.054-5.38$ & 0.016 & 1.170 & 0.987 & $13 \%$ & 0.047 \\
\hline Syringic acid & $0.053-5.34$ & -0.002 & 2.371 & 0.980 & $16 \%$ & 0.025 \\
\hline Syringyl aldehyde & $0.036-3.64$ & 0.019 & 2.081 & 0.992 & $10 \%$ & 0.088 \\
\hline Acetosyringone & $0.036-3.64$ & 0.019 & 2.081 & 0.992 & $10 \%$ & 0.025 \\
\hline Syringylacetone & $1.17-117$ & -0.050 & 2.951 & 0.996 & $9 \%$ & 0.004 \\
\hline Retene & $0.290-14.5$ & -0.217 & 1.871 & 0.997 & $7 \%$ & 0.008 \\
\hline Isopimaric acid & $0.142-14.2$ & 0.043 & 0.155 & 0.997 & $12 \%$ & 0.037 \\
\hline Dehydroabietic acid methyl ester & $0.392-19.6$ & 0.007 & 1.315 & 1.000 & $1 \%$ & 0.005 \\
\hline Dehydroabietic acid & $0.142-14.2$ & 0.074 & 0.267 & 0.997 & $9 \%$ & 0.030 \\
\hline Abietic acid & $0.022-2.20$ & 0.023 & 0.557 & 0.983 & $14 \%$ & 0.102 \\
\hline 7-Oxodehydroabietic acid & $0.142-14.2$ & 0.043 & 0.155 & 0.997 & $12 \%$ & 0.037 \\
\hline Divanillyl & $0.392-19.6$ & 0.007 & 1.315 & 1.000 & $1 \%$ & 0.014 \\
\hline
\end{tabular}

The chromatographic separation for solvent extracted (SE) samples was carried out on a Varian GC 3400 (Varian, USA) assembled with a retention gap (guard column), deactivated fused silica, $2.5 \mathrm{~m}, 0.22 \mathrm{~mm}$ ID (SGE) and a BPX5 column, $25 \mathrm{~m}, 0.22 \mathrm{~mm}$ ID, $0.25 \mu \mathrm{m}$ film (SGE). The sector field mass spectrometer MAT95 (Thermo Scientific, Germany) was operated in multiple ion detection mode (MID) for target analysis.

\subsection{Solvent extraction of polar compounds}

Solvent extraction of polar compounds was carried out with dichloromethane/methanol $(1: 1, \mathrm{v} / \mathrm{v})$ in an ultrasonic bath. Prior to extraction the samples were spiked with internal standard mixtures. Ultrasonication was carried out three times with five millilitres of solvent for fifteen minutes each. The three extracts were combined and filtered over PTFE 
syringe membrane filters $(0.2 \mu \mathrm{m}$, Sartorius, Germany). Solvent was evaporated to dryness. Derivatization was started by adding MSTFA to the samples. Reaction time was $3 \mathrm{~h}$ at $80^{\circ} \mathrm{C}$. Samples were measured with the same GC-TOFMS equipment as described above for IDTD-GC-TOFMS which was also used for thermal desorption. The injector employed was also capable of liquid injection (here one injection equates to $0.5-1 \mathrm{~m}^{3}$ of sampled air). The GC method was programmed as follows: Injector temperature: $300^{\circ} \mathrm{C}$, Oven temperature: $100^{\circ} \mathrm{C}$ for $1 \mathrm{~min}$. Heating rates were $25^{\circ} \mathrm{C} \mathrm{min}-1$ to $175^{\circ} \mathrm{C}$ followed by a rate of $5^{\circ} \mathrm{C} \mathrm{min}^{-1}$ to $330^{\circ} \mathrm{C}$ with an isothermal of $15 \mathrm{~min}$ at $330^{\circ} \mathrm{C}$ at the end of the run.

Calibration for liquid extraction samples was carried out by evaporating different standard dilutions to dryness. MSTFA was added directly to the dried standard. The further procedure was like the sample treatment.

\section{Results and discussion}

\subsection{Derivatization}

MSTFA as silylation reagent for the IDTD method has the advantage that it is not necessary to be removed from the sample before GC-MS analysis. MSTFA itself and the products of MSTFA reactions exhibit high vapour pressures. Even at room temperature a significant enrichment of carrier gas with MSTFA is possible. On non-polar capillary columns MSTFA has characteristics like many other solvents being used for solvent injection in GC-MS. Thus short retention times with sharp solvent peaks without carry over are achievable. At usual conditions (e.g. temperature of $80^{\circ} \mathrm{C}$ ) MSTFA is reacting relatively slow. Sterically hindered molecules exhibit poor reaction yields with MSTFA. For that reason a catalyst like chlorotrimethylsilan (TMCS) which acts as Lewis acid may be used to accelerate the reaction. Combinations such as BSTFA (N,N'-bistrimethylsilyl-trifluoroacetamide) and TMCS (99/1, v/v) or MSTFA and TMCS (99/1, v/v) are widely used for derivatization particularly for determination of levoglucosan and other polar compounds in atmospheric aerosol (Nolte, 2001; Simoneit, 1999; Zdrahal, 2002). Due to a large polar organic fraction and inorganic salts ambient aerosol samples also contain water. Water is also involved in reactions with silylation reagents. This leads to two essentials for derivatization reaction with ambient aerosol: first, a sufficient surplus of derivatization agent is necessary and second, TMCS has to be excluded for in-situ reactions in the gas chromatography system. Poor column life time could be a result of high reaction yields of $\mathrm{HCl}$ formed by water and TMCS. To avoid possible degradation reactions of derivatized compounds with water a surplus of MSTFA is necessary. This is ensured when working with dampen of filters followed by enrichment of carrier gas with MSTFA. A high water content of samples collected on quartz fibre filters was visible when working without solvent delay during mass spectrometric detection. The mass signals during thermal desorption were indicated by a large signal at $\mathrm{m} / \mathrm{z} 147$ caused by hexamethyldisiloxane. Without a surplus of MSTFA the water content could be responsible for a competitive reaction next to derivatization of analytes and water can also react with already derivatized analytes during derivatization/desorption process.

To accelerate the reaction an increase of temperature can be applied instead of catalysts. In the presented method the high temperatures of thermal desorption increase reaction rate when working with MSTFA. IDTD utilized only 16 minutes of desorption time for derivatization reaction. The same reaction yields were obtained with the SE method when derivatization was performed for $3 \mathrm{~h}$. A verification of derivatization yields was done by comparison of responses of isotope-labelled standards generated with the IDTD method and with directly derivatized standard solution as used for the here described calibration curves of SE methods. Therefore, a recovery efficiency standard $\left(\mathrm{D}_{42}\right.$-eicosane) was added to the samples prior to injection to normalise abundance of polar standard compounds by this non-polar standard compound which was even not affected by sample pre-treatment. Assuming that derivatization reactions in solution were complete $(100 \%)$ the yields for IDTD were calculated relative to yields of derivatization in solution. The derivatization yields of vanillin (111\%), levoglucosan (97\%) and palmitic acid $(107 \%)$ suggest that reactions of both methods were comparable.

It was found that reactions take place in multiple ways. Therefore the two step derivatization procedure was developed. For the silylation of multifunctional molecules or polycyclic polar compounds like anhydrous sugars on the one side or sterols on the other side the soak of sample with MSTFA is necessary. Some phenols (e.g. sinapinic acid) were only accessible when working with enrichment of carrier gas with MSTFA. Resin acids were found to be only accessible when working with both steps of the derivatization procedure. Experiments with a direct inlet to a mass spectrometer will provide clearness about formation of reaction products and possible competitive or degradation reactions.

The first derivatization step (the moistening of the filter with MSTFA) was introduced as described before to start the reaction and to protect the compounds until the MSTFA-saturated helium enters the injection port of the gas chromatograph. The enrichment of carrier gas with volatile derivatization reagent has several advantages. (1) A steady flow of MSTFA during thermal desorption protects derivatized polar organic compounds from degradation until the transfer to the gas chromatograph is completed. (2) Derivatization products are removed immediately from the reaction medium. (3) Equilibrium can be prevented and a high yield of conversion is possible. (4) The surplus of MSTFA is maintained until derivatization and thermal desorption are finalized. (5) An improvement of response of 


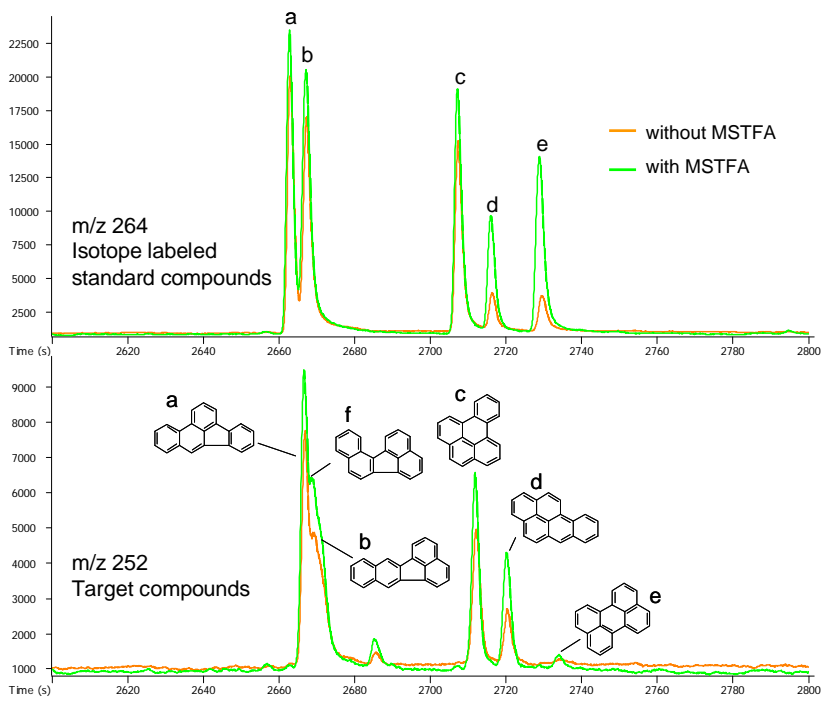

Fig. 3. The effect of filter matrix and MSTFA on sensitivity of PAH analysis. Orange line: $108 \mathrm{~mm}^{2}$ filter of sampled $\mathrm{PM}_{1}$ (equivalent to 2001 aerosol) analysed without MSTFA. Green line: $108 \mathrm{~mm}^{2}$ filter of sampled $\mathrm{PM}_{1}$ (equivalent to 2001 aerosol) analysed with MSTFA-saturated carrier gas during thermal desorption. The mass trace $\mathrm{m} / \mathrm{z} 264$ is shown for the isotopelabelled internal standards of (a) benzo[b]fluoranthene $(0.802 \mathrm{ng})$, (b) benzo[k]fluoranthene (1.04 ng), (c) benzo[e]pyrene $(0.802 \mathrm{ng})$, (d) benzo[a]pyrene $(1.04 \mathrm{ng})$, (e) perlyene $(1.12 \mathrm{ng})$. Below the mass trace $\mathrm{m} / \mathrm{z}, 252$ is shown for the corresponding native compounds with the exception that (a) benzo[b]-, (f) benzo[j]- and (b) benzo[k]fluoranthene could not be separated.

components suspected to be sensitive for artefact formation at thermal desorption conditions can be recognized. For instance, low volatile PAH like benzopyrenes and perylene showed a higher response when the MSTFA saturated carrier gas flow was switched on during thermal desorption even without moistening of the filters with MSTFA before thermal desorption. The explanation for this effect is the deactivation of active surfaces e.g. on the quartz fibres. Figure 3 shows an example for a low volume ambient aerosol sample (2001 of sampled air) spiked with isotope labelled standard substances when measured with and without MSTFA-saturated carrier gas. The example was taken from a series of $\mathrm{PM}_{1}$ filter samples with sampling on hourly basis. The PM deposits on the filters were quite low. Therefore, a larger part of the filter sample was applied for thermal desorption $\left(108 \mathrm{~mm}^{2}\right.$ in contrast to $27 \mathrm{~mm}^{2}$ for $24 \mathrm{~h}$ samples). A two-fold response improvement was found for some compounds when working with MSTFA saturated carrier gas. This was especially the case for the reactive compounds benz[a]pyrene and perylene without affecting quantification results. The positive effect (resulting in a lower limit of quantification (LOQ)) was verified by eighteen additional samples of $\mathrm{PM}_{1}$ filter samples collected hourly.
Nevertheless, MSTFA may also be responsible for some artefacts like adducts with aldehydes (Blau, 1977; Halket, 2003; Little, 1999). Derivatization adducts are formed by enols originating from aldehydes with an $\alpha$-hydrogen atom. Electron impact mass spectra therefore show ions with fragments at $m / z, 228\left(\mathrm{C}_{7} \mathrm{H}_{13} \mathrm{O}_{2} \mathrm{NF}_{3} \mathrm{Si}^{+}\right)$and $m / z, 184$ $\left(\mathrm{C}_{5} \mathrm{H}_{9} \mathrm{ONF}_{3} \mathrm{Si}^{+}\right)$. For aromatic aldehydes like vanillin, coniferyl aldehyde and syringyl aldehyde, however, no formation of adducts was observed.

\subsection{Calibration}

Calibration curves of IDTD were very similar to the solvent extraction method. Precision is better for calibration curves of SE due to the fact that standard solutions were directly used for calibration. Whereas for thermal desorption methods calibration reasonably is carried out by standard addition to reference filters. Thus response differences due to matrix effects are minimized. For that reason some calibration regressions exhibit a considerable offset. The intercept depends on the concentration of components on the reference filters. Regression curve data are specified in Table 1.

Calibrations were done with the according isotopelabelled standards and the native compounds with high purity as far as possible (Table S1). Only three different isotopelabelled polar substances were applicable, namely ${ }^{13} \mathrm{C}_{6}$ vanillin, ${ }^{13} \mathrm{C}_{6}$-levoglucosan and $\mathrm{D}_{31}$-palmitic acid. As most substances analysed here were available in sufficient purity, only an isotope-labelled internal surrogate standard had to be applied. However, some substances described here (e.g. dehydroabietic acid, syringyl aldehyde, divanillyl) were not available in sufficient purity. Moreover, no isotope-labelled analogues were available. Thus, only semi-quantitative results using surrogates were obtained for these compounds. Applied surrogates are specified in Table S1, too. Due to different responses of compounds caused by different extraction and derivatization yields the range of application of isotope-labelled compounds as internal standard for further substances is limited. Moreover, those compounds should exhibit equal chromatographic properties and similar fragmentation characteristics when treated by electron-impact ionization. For these reasons only compounds very similar to the anhydrous sugars levoglucosan, mannosan and galactosan can be quantified properly with ${ }^{13} \mathrm{C}_{6}$-levoglucosan as internal standard. $\mathrm{D}_{31}$-palmitic acid was used mainly for acids, aldehydes and ketones. Even some deuterated PAH were used as internal standard for some polar compounds characterized by a two-ring (divanillyl) or three-ring structure (isopimaric acid). ${ }^{13} \mathrm{C}_{6}$-vanillin was used as standard only for its native form. Experiments with vanillic acid and vanillic acid methyl ester were not successful in receiving an adequate calibration curve with ${ }^{13} \mathrm{C}_{6}$-vanillin as internal standard. 

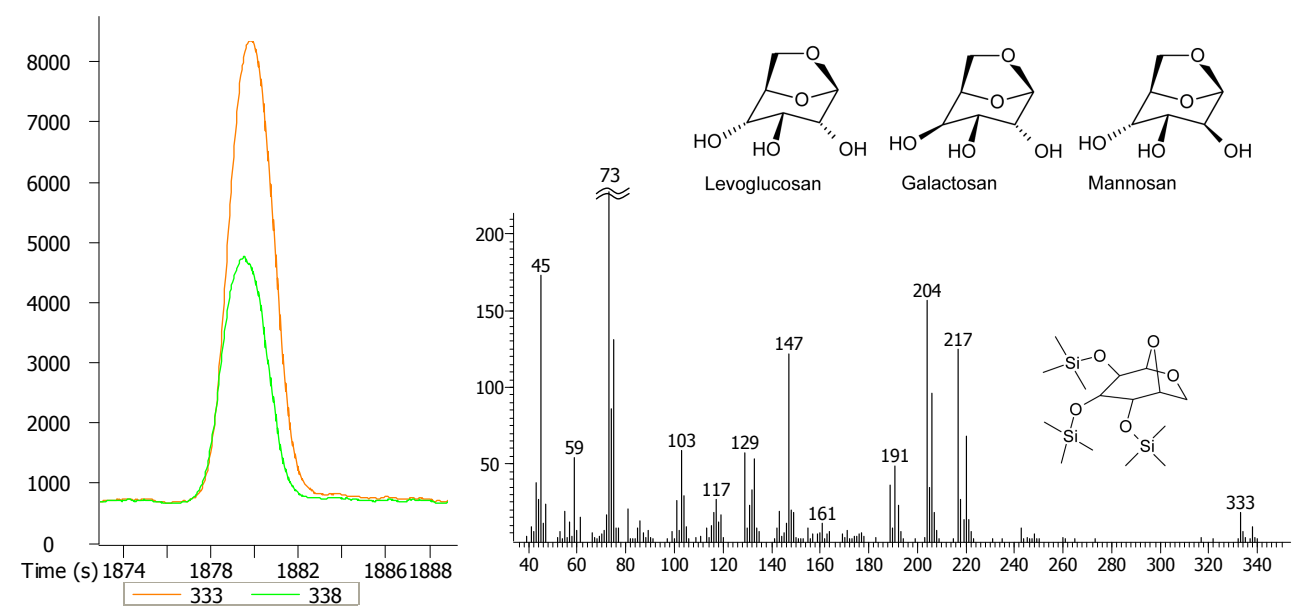

Fig. 4. Levoglucosan: Structural differences of levoglucosan and its isomers (top right). Left side: coelution of silylated native levoglucosan (orange line) and the silylated isotope labelled ${ }^{13} \mathrm{C}_{6}$-levoglucosan (green line) in the chromatogram. Right side: The mass spectra of the chromatogram at maximum of the isotope labelled levoglucosan.

Levoglucosan showed good linearity in calibration curves over the whole working range of 3.5-350 ng Levoglucosan per analysis. The slope is similar to that of the calibration curve of the solvent extraction method shown in Table S2. It also shows the intercept of the IDTD method caused by standard addition to a reference sample. The precision of both methods is quite good: $6 \%$ for thermal desorption and $4 \%$ for SE. The limit of detection is somewhat higher for IDTD compared to SE (0.6 ng and $0.1 \mathrm{ng}$, respectively). Other studies using GC-MS methods obtained precisions of $20 \%$ (Graham et al., 2002 and 2003), $5 \%$ (Simpson et al., 2004) and 2-5\% (Pashynska, 2002). In the presented study mass fragments at $\mathrm{m} / \mathrm{z} 217$ and $220\left({ }^{13} \mathrm{C}_{6}\right.$-levoglucosan) were used for quantification. Quantification with the base peak pair at $\mathrm{m} / \mathrm{z} 204$ and 206 is not recommended due to the relatively small retention time shift for ${ }^{13} \mathrm{C}_{6}$-levoglucosan. High resolution mass spectrometers are necessary to separate isotopes in that case. Due to its ubiquity in the atmosphere with even high concentrations during summer time also fragments at $m / z 333$ respectively 338 can be used for quantification (Fig. 4).

Other polar compounds than levoglucosan exhibit good linear fittings, too. However, sensitivity of some polar compounds is quite poor, especially for small molecules like succinic acid, malic acid, or guaiacol. Therefore, Table 1 shows the calibration data of malic acid as an example for these compounds with a relative low slope of 0.033 compared to 0.228 for the solvent extraction method. This short chain multifunctional acid is also discussed in the comparison of the methods applied for ambient aerosol samples. The correlation of quantitative results from IDTD with the solvent extraction method was quite good with a slope of the correlation regression near one (see Sect. 3.4). Precision for malic acid for both methods was near $10 \%$. Some com- pounds in low concentrations exhibit higher variation coefficients up to $17 \%$, especially syringic acid (16\%) and vanillic acid methyl ester $(17 \%)$.

Usually PAH and oxidized PAH (o-PAH) are not affected by the derivatization procedure. Although an improvement of sensitivity was observed like described in Sect. 3.1 derivatization had no influence on quantification. Most calibration regression curves are showing good linearity with similar sensitivities for IDTD and SE. No generation of artefacts were observed neither when comparing the in-situ derivatization procedure with the usual thermal desorption procedure nor when comparing both thermal desorption methods with a solvent extraction procedure. Moreover, the calibrations of the thermal desorption methods were almost applicable for solvent extraction methods. Only anthracene shows variation coefficients higher than $10 \%$ induced by the poor response of anthracene in GC-MS. Other PAH exhibit variation coefficients below $10 \%$. This is because of the application of the respective isotope-labelled standards for each PAH (Table S1). For o-PAH similar observations were made. 9,10-Anthracenedione and benzo[a]anthracene7,12-dione have low variation coefficients $(2 \%$ and $9 \%$, respectively). For these two o-PAH the according isotopelabelled standards were applied. Especially 9H-fluoren-9one and cyclopenta[def]phenanthrenone show higher variations though adequate isotope-labelled surrogates were used. $\mathrm{D}_{10}$-phenanthrene and $\mathrm{D}_{12}$-benzo[a]anthracene were used in these cases due to best regression fittings.

\subsection{Comparison of methods based on the analysis of SRM 1649a}

The DTD method was employed in studies already published by Schnelle-Kreis et al. (2005a, b, 2007). The standard deviation of results $(n=5)$ for all compounds with DTD was 
Table 2. Concentration of PAH in NIST Standard Reference Material 1649a (Urban Dust).

\begin{tabular}{|c|c|c|c|c|c|c|c|c|}
\hline \multirow{3}{*}{ Mean value mass of urban dust $[\mu \mathrm{g}]$} & \multicolumn{2}{|c|}{ SE-GC-MS } & \multicolumn{2}{|c|}{ DTD-GC-MS } & \multicolumn{2}{|c|}{ IDTD-GC-MS } & \multicolumn{2}{|c|}{ Certified Values } \\
\hline & \multicolumn{2}{|l|}{14.8} & \multicolumn{2}{|l|}{62.5} & \multicolumn{2}{|l|}{46.3} & \multirow[b]{2}{*}{ Mean conc. } & \multirow[b]{2}{*}{ 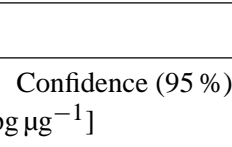 } \\
\hline & 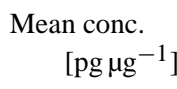 & $\mathrm{SD}$ & $\begin{array}{l}\text { Mean conc. } \\
\qquad\left[\mathrm{pg} \mu \mathrm{g}^{-1}\right]\end{array}$ & $\mathrm{SD}$ & $\begin{array}{l}\text { Mean conc. } \\
\qquad\left[\mathrm{pg} \mu \mathrm{g}^{-1}\right]\end{array}$ & $\mathrm{SD}$ & & \\
\hline Phenanthrene & 4.52 & 0.52 & 5.10 & 0.64 & 5.36 & 0.53 & 4.14 & 0.37 \\
\hline Anthracene & 0.53 & 0.04 & 1.99 & 0.40 & 0.98 & 0.17 & 0.43 & 0.08 \\
\hline Fluoranthene & 6.21 & 0.33 & 6.19 & 1.24 & 6.07 & 0.93 & 6.45 & 0.18 \\
\hline Pyrene & 5.32 & 0.26 & 5.47 & 0.99 & 5.15 & 0.81 & 5.29 & 0.25 \\
\hline Benzo[a]anthracene & 1.97 & 0.32 & 2.21 & 0.50 & 1.93 & 0.25 & 2.21 & 0.07 \\
\hline Chrysene & 4.70 & 0.53 & 4.47 & 0.40 & 4.28 & 0.69 & 4.41 & 0.08 \\
\hline Benzo[b]fluoranthene & 8.65 & 0.62 & $12.51^{\mathrm{a}}$ & 1.12 & $11.71^{\mathrm{a}}$ & 1.18 & 6.45 & 0.64 \\
\hline Benzo[k]fluoranthene & 2.16 & 0.13 & & & & & 1.93 & 0.03 \\
\hline Benzo[e]pyrene & 3.07 & 0.25 & 3.35 & 0.57 & 2.83 & 0.75 & 3.09 & 0.19 \\
\hline Benzo[a]pyrene & 2.16 & 0.29 & 3.51 & 0.61 & 2.60 & 0.41 & 2.51 & 0.09 \\
\hline Perylene & 0.68 & 0.11 & 1.27 & 0.53 & 0.44 & 0.10 & 0.65 & 0.08 \\
\hline Indeno[1,2,3-cd]pyrene & 2.73 & 0.31 & 3.11 & 0.52 & 2.87 & 0.77 & 3.18 & 0.72 \\
\hline Dibenzo[a,h]anthracene & 0.62 & 0.09 & $\mathrm{~b}$ & & 0.88 & 0.23 & 0.29 & 0.02 \\
\hline Benzo[g,h,i]perylene & 4.11 & 0.28 & 3.79 & 0.28 & 3.95 & 0.47 & 4.01 & 0.91 \\
\hline
\end{tabular}

${ }^{\mathrm{a}}$ sum of benzo[b]fluoranthene, benzo[j]fluoranthene and benzo[k]fluoranthene; ${ }^{\mathrm{b}}$ not quantified.

Table 3. Concentration of levoglucosan, mannosan and galactosan in NIST Standard Reference Material 1649a (Urban Dust). A comparison with other publications.

\begin{tabular}{|c|c|c|c|c|c|c|c|c|}
\hline & & & \multicolumn{2}{|c|}{ Levoglucosan } & \multicolumn{2}{|l|}{ Mannosan } & \multirow{2}{*}{\multicolumn{2}{|c|}{$\begin{array}{r}\text { Galactosan } \\
\text { Mean conc.\& SD } \\
{\left[\mathrm{pg} \mu \mathrm{g}^{-1}\right]}\end{array}$}} \\
\hline & Method & $n$ & $\begin{array}{l}\text { Mean conc. } \\
\qquad\left[\mathrm{pg} \mu \mathrm{g}^{-1}\right.\end{array}$ & $\mathrm{SD}$ & $\begin{array}{l}\text { Mean conc. } \\
\qquad\left[\mathrm{pg} \mu \mathrm{g}^{-1}\right]\end{array}$ & SD & & \\
\hline This study & IDTD-GC-TOF MS & 3 & 165 & 1.4 & 20.5 & 1.0 & 10.8 & 1.8 \\
\hline Larsen et al. (2006) & $\mathrm{PFE}^{\mathrm{a}}$ GC-MS & 3 & 162 & 8 & - & - & - & - \\
\hline Louchouarn et al. (2009) & $\mathrm{PFE}^{\mathrm{b}}$ GC-MS & 4 & 160.5 & 4.7 & 17.3 & 1.0 & 5.0 & 0.3 \\
\hline Kuo et al. (2008) & $\mathrm{PFE}^{\mathrm{b}}$ GC-MS & 11 & 163.9 & 11.8 & - & - & - & - \\
\hline
\end{tabular}

${ }^{a}$ Pressurized fluid extraction with ethyl acetate, derivatization with BSTFA/TMCS, derivatization with BSTFA/TMCS (99/1, v/v), Larsen (2006); ${ }^{b}$ Pressurized fluid extraction with CH2Cl2/CH3OH (9/1, v/v), derivatization with BSTFA/TMCS (99/1, v/v), Kuo (2008).

smaller than $20 \%$ except for perylene and anthracene which were near the limits of detection. This is due to their low content in the reference material and the small amount of about $60 \mu \mathrm{g}$ which was used for thermal desorption (this means a total mass of anthracene of $26 \mathrm{pg}$ and $39 \mathrm{pg}$ of perylene, respectively). Similar effects were described by van Drooge et al. (2009). More crucial seems the fact that the concentrations of benzo[a]pyrene, an important marker for several emission sources and with high carcinogenic potential, were overestimated by $40 \%$ of the certified value. This phenomenon was not observed when using the IDTD method. Especially benzo[a]pyrene and perylene seem to be susceptible for degradation of spiked internal standards.

Nevertheless, the results are satisfying with respect to the low amounts of SRM in analysis. Other studies used at least $500 \mu \mathrm{g}$ (Gil-Moltó, 2009), $900 \mu \mathrm{g}$ up to $1.9 \mathrm{mg}$ (Ho, 2008), or $3 \mathrm{mg}$ (Waterman, 2000) of urban dust for thermal desorption.
Only van Drooge et al. analysed lower SRM 1649a quantities (van Drooge, 2009) ranging from $60 \mu \mathrm{g}$ to $550 \mu \mathrm{g}$. Results are visualized in Table 2 and Fig. S1.

The concentration of levoglucosan contained in SRM 1649a was already measured and published (Kuo, 2008; Larsen, 2006; Louchouarn, 2009). Although the standard reference materials were not certified for levoglucosan it is possible to use them for laboratory inter comparison. In this study a determination of levoglucosan and its analogues mannosan and galactosan was carried out the same way as for filter samples with IDTD. Measured values for levoglucosan were comparable with values already published (Table 3). Concentrations of mannosan and galactosan have only been published by Louchouarn et al. (Louchouarn, 2009). Our results for mannosan were comparable with the published, whereas the concentrations of galactosan were more than two times higher $\left(10.8 \mu \mathrm{g} \mathrm{g}^{-1}\right.$ in this study and $5.0 \mu \mathrm{g} \mathrm{g}^{-1}$ 
Phenanthrene

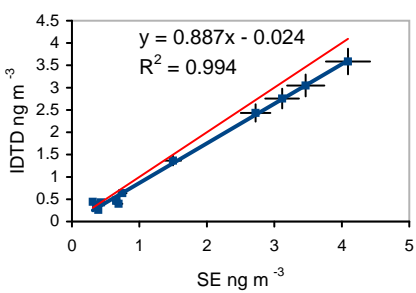

Benz[a]anthracene

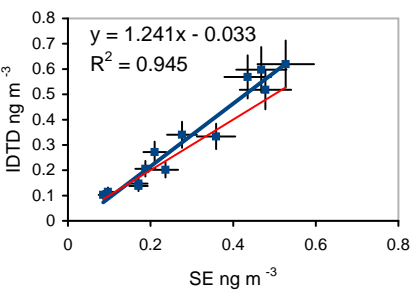

sum of Benzofluoranthenes

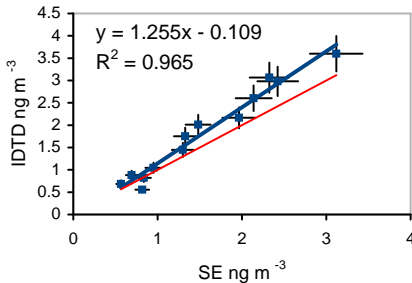

Perylene

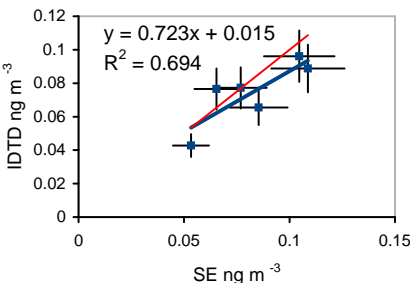

Fluoranthene

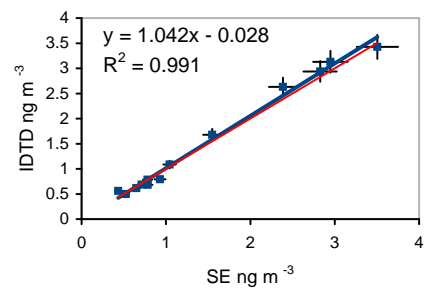

Chrysene and Triphenylene

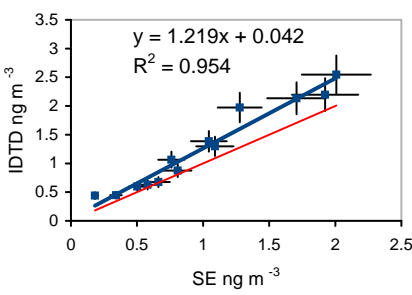

Benz[e]pyrene

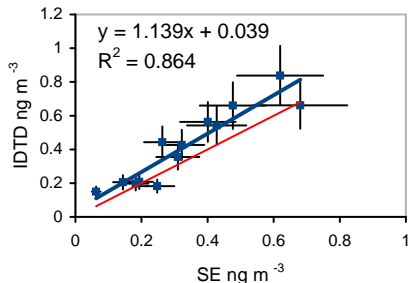

Indeno[1,2,3-cd]pyrene

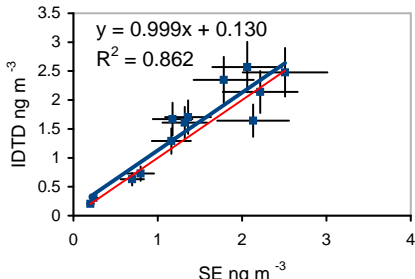

Pyrene

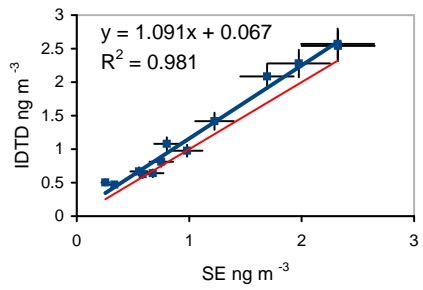

Retene

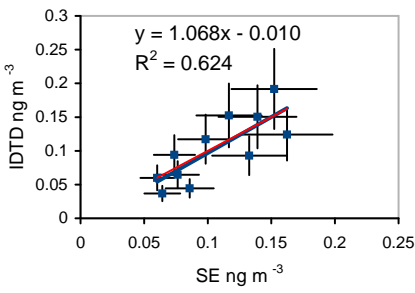

Benz[a]pyrene

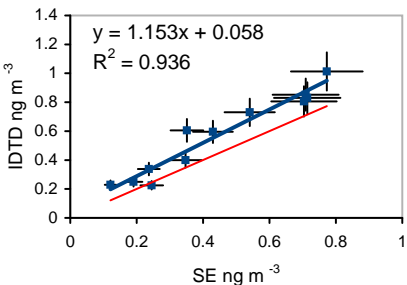

Benzo[ghi]perylene

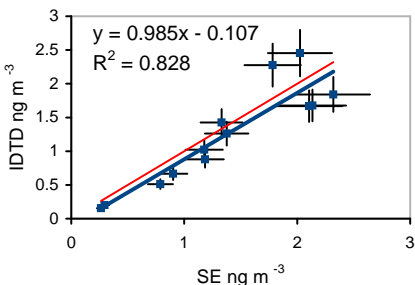

Fig. 5a. Correlation of IDTD and SE for analysis of PAH in ambient aerosol samples (blue: linear regression, red: line through origin, slope 1).

found by Louchouarn et al. respectively). The main difference of the methods is the manner of extraction. Louchouarn et al. employed a pressurized fluid extraction with an accelerated solvent extraction system. Due to the similarity of the anhydrous sugars we doubt that this difference could be an extraction artefact. The observed ratio of levoglucosan/mannosan/galactosan was similar as found for ambient aerosol by Ma et al. (2010) (15:3:1 v/v/v).

\subsection{Comparison of the methods based on ambient aerosol samples}

A comparison of the in-situ derivatization thermal desorption method and an ultrasonic extracting method followed by a derivatization step in solution (SE) was carried out. Correlations of quantitative results are demonstrated. This is visualized by plotting the result of IDTD analysis against concentrations determined by solvent extraction (x-axis). Both methods show good comparability for most PAH (Fig. 5a). The correlations indicate good linearity with a slope of nearly one or slightly higher with the exception of phenanthrene and perylene ( $11 \%$ respectively $31 \%$ below results of SE). These compounds showed higher concentrations when analysed by solvent extraction. Van Drooge et al. (2009) found values for phenanthrene $35 \%$ over a liquid extraction method when working with a thermal desorption method. Also Ho and $\mathrm{Yu}$ (2004) found $33 \%$ higher values when analyzing 


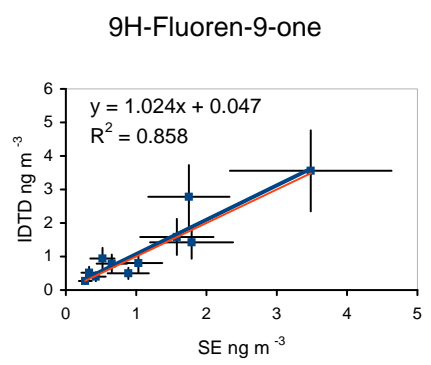

Cyclopenta[def]phenanthren-

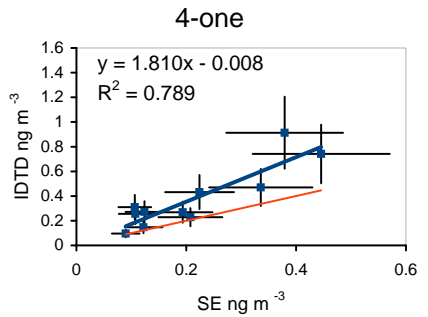

Dehydroabietic acid, methyl ester

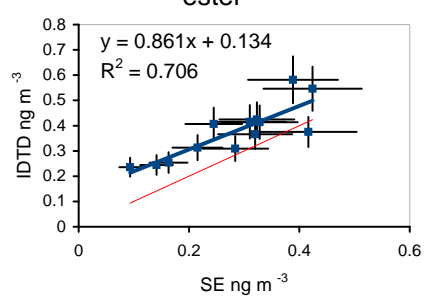

9,10-Anthracenedione

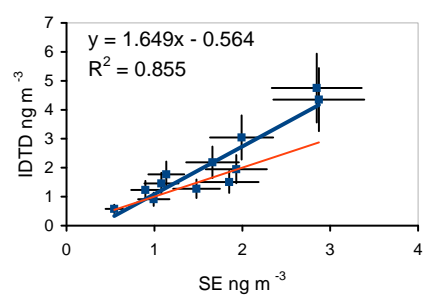

11H-Benzo[a]fluoren-11-one

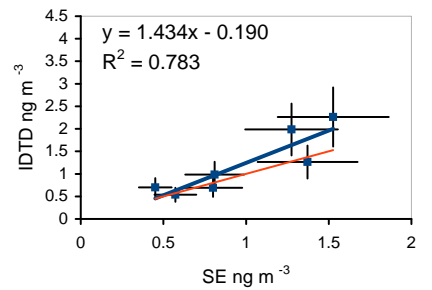

1,4-Naphthalic anhydride

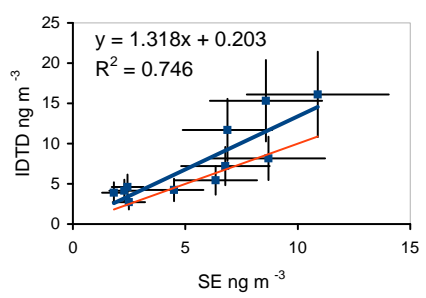

11H-Benzo[b]fluoren-11-one

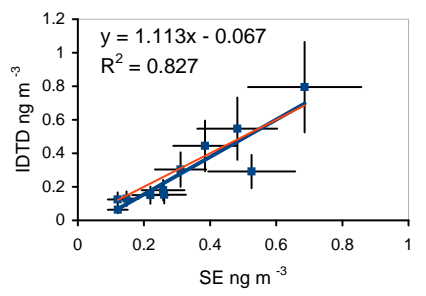

Fig. 5b. Correlation of IDTD and SE for analysis of o-PAH and dehydroabietic acid methyl ester in ambient aerosol samples (blue: linear regression, red: line through origin, slope 1).

phenanthrene in aerosol samples with an in-injector thermal desorption technique. Usually phenanthrene and anthracene exhibit higher variations due to their low boiling point and low concentration in the particulate phase. Nevertheless, correlation of IDTD and SE was quite good. The data of fluoranthene and pyrene exhibited the highest correlation of all PAH analysed, whereas for benzo[a]anthracene $24 \%$, chrysene (and triphenylene) $22 \%$ and the benzofluoranthenes $26 \%$ higher concentrations were determined with IDTD. These findings are comparable to those of $\mathrm{Ho}$ and $\mathrm{Yu}$ (2004) who determined $36 \%$ higher values for benz[a]anthracene and $19 \%$ higher values for chrysene in their study. Ho et al. (2008) found a higher correlation coefficient for PAH than in their previous study (Ho and Yu, 2004) with the same desorption technique. The concentration ranges in their study, 2004, were in the same order of magnitude like in this study. In their recent study from 2008 concentration values were about ten times higher.

Benzo[a]pyrene (15\% higher values with IDTD) which is known to be more reactive showed no difference in behaviour in this study compared to benzo[e]pyrene (14\% higher). These benzopyrenes showed higher concentrations when analysed by thermal desorption. The lower concentrations of perylene when analysed by IDTD may be a result of low concentrations of perylene in ambient aerosol samples being also indicated by a poor correlation coefficient $\left(R^{2}=0.69\right)$. Indeno[1,2,3-cd]pyrene and Benzo[ghi]perylene showed good comparability but with somewhat higher variations $\left(R^{2}=0.86\right.$ respectively 0.83$)$.

Comparability of the analytical methods is also demonstrated for oxidized PAH (Fig. 5b). For o-PAH only two isotope-labelled standards were applied. The higher variation coefficients of calibration curves indicate a lower precision of analysis of o-PAH for both methods. An influence on analysis of field samples is therefore not avoidable. 9H-fluoren-9-one and 11H-benzo[b]fluoren-11-one showed good correlation and a slope near unity for the comparison of IDTD and SE. 9H-fluoren-9-one showed $2 \%$ higher values and $11 \mathrm{H}$-benzo[b]fluoren-11-one $11 \%$ higher values when analyzed by IDTD. Ho et al. (2008) also found good results for 9H-fluoren-9-one (13\% lower values with TD) and for benz[a]anthracene-7,12-dione (not demonstrated in this study due to low concentrations). On the other hand higher values of other o-PAH determined were observed when being analysed by the in-situ derivatization thermal desorption. 9,10-Anthracenedione, 1,4-naphthalic 
Malic acid

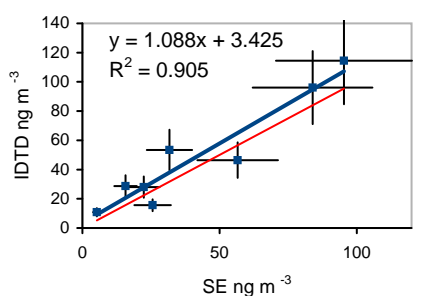

Mannosan

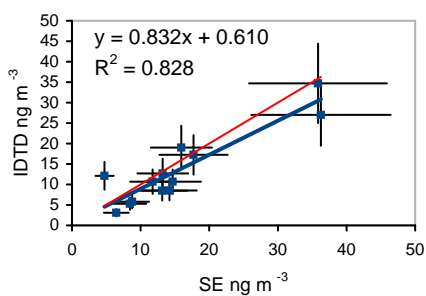

Vanillic acid

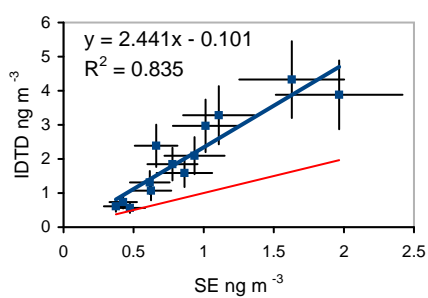

Isopimaric acid

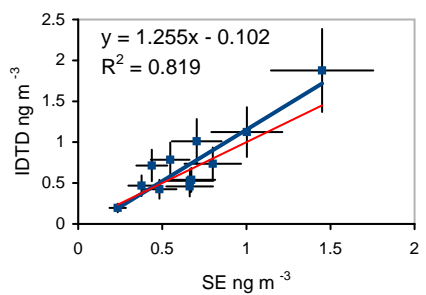

Phthalic acid

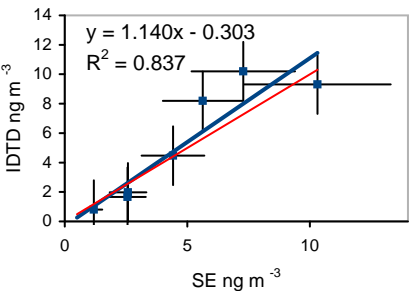

Levoglucosan

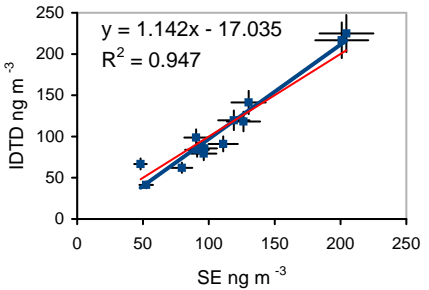

Syringic acid

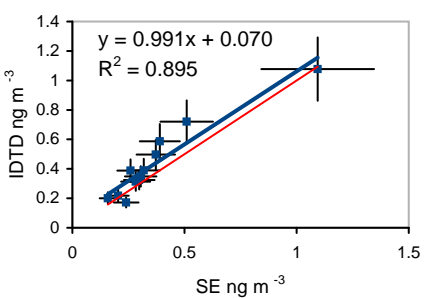

Dehydroabietic acid

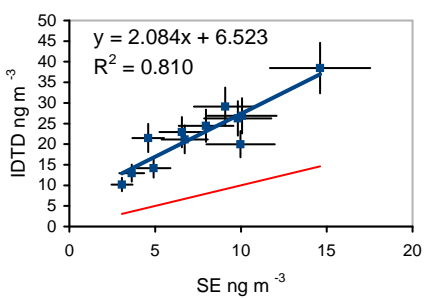

Galactosan

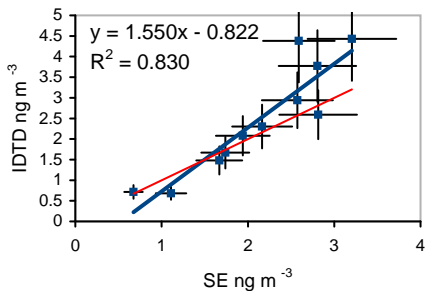

Acetosyringone

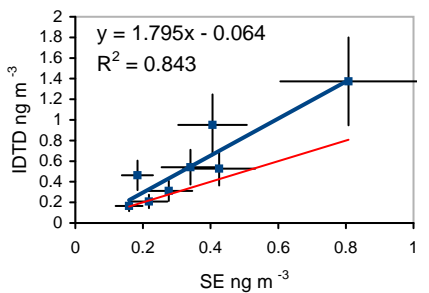

Divanillyl

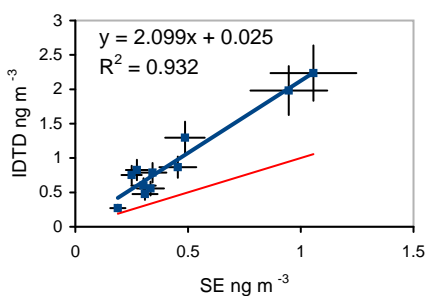

Abietic acid

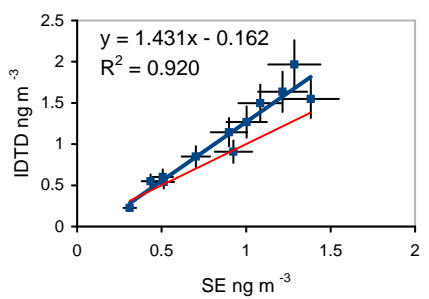

Fig. 5c. Correlation of IDTD and SE for analysis of polar substances in ambient aerosol samples (blue: linear regression, red: line through origin, slope 1).

anhydride, cyclopenta[def]phenanthren-4-one and $11 \mathrm{H}-$ benzo[a]fluoren-11-one showed similar correlation coefficients but concentrations were at least $30 \%$ higher when analysed with IDTD compared to SE. Neither a loss of analytes by solvent extraction nor a generation of o-PAH from PAH at thermal desorption conditions can be excluded. An underestimation of analyte concentrations determined by solvent extraction seems to be possible as a result of a different extraction efficiency of spiked standards and native sample compounds.

For selected polar organic compounds, especially wood combustion tracers, IDTD was applied to ambient aerosol samples, the results being compared with SE. For all com- pounds with concentrations above the limit of detection (LOD) in most collected ambient aerosol samples the correlation to solvent extracted ones is demonstrated (Fig. 5c). A good correlation and a slope near unity were found for levoglucosan. Ma et al. (2010) showed also good comparability of their fast two-dimensional GC-MS technique with SE for levoglucosan without derivatization by analyzing biomass burning aerosol.

The correlations of galactosan and mannosan were not as good by far. Due to advantages of levoglucosan in forming silylation products it can be assumed that derivatization yields were higher for levoglucosan compared to those of mannosan and galactosan. Levoglucosan provides three 
functional hydroxyl groups which are located in alternating planes. Its isomers mannosan and galactosan have each two neighbouring hydroxyl groups which are in the same plane (Fig. 4). These hydroxyl groups maybe steric hindered when substituted by trimethylsilyl groups. Therefore the reaction rate and yield of the three anhydrous sugars could be rather different due to their stereo isomeric differences. The concentrations of these sugars in the ambient air samples were all in the linear range of their calibration curve using 13C6levoglucosan as internal standard. Hence no differences in correlation of comparison of IDTD/SE were observed.

The resin derived compounds dehydroabietic acid and dehydroabietic acid methyl ester were other compounds being present in all ambient aerosol samples. These compounds are reaction products of wood combustion generated by dehydrogenation and oxidation of resin acids originating from colophony of conifers (Leithead, 2006; Nolte, 2002). Both substances were quantified using $\mathrm{D}_{10}$-pyrene as internal standard. Isopimaric acid was used as surrogate for external calibration of dehydroabietic acid. Pyrene was used for external calibration of dehydroabietic acid methyl ester already exhibiting a protected carboxylic group and therefore not being affected by derivatization. The results for dehydroabietic acid, dehydroabietic acid methyl ester and abietic acid showed up to two times higher values when analysed by IDTD. Correlations are not even roughly as good as for substances with according isotope-labelled internal standard but were still acceptable. But correlation coefficients were in the same range like the other resin acids abietic acid and isopimaric acid. These acids were calibrated using respective standards. Here the lower correlation coefficients were a result of low concentrations in ambient aerosol.

Beside levoglucosan especially for the relatively small acids syringic acid, phthalic acid and malic acid a good consistency of the two methods could be observed. On the other hand twofold higher concentrations of the lignin combustion products acetosyringone, vanillic acid and divanillyl were found when analysed by IDTD-GC-TOFMS, as was the case for dehydroabietic acid. An interesting fact is the lack of consistency for syringic acid and vanillic acid. These similar molecules exhibited different results when analysed with IDTD and SE. Both acids were calibrated and analysed by applying $\mathrm{D}_{31}$-palmitic acid as internal standard (Table $\mathrm{S} 1$ ).

Experiments with different isotope-labelled standards substantiate the suspicion that in some cases extraction efficiency was poor when using ultrasonic-assisted extraction in dichloromethane/methanol $(1 / 1, v / v)$. The use of this solvent mixture is a compromise to achieve sufficient extraction yields of all analytes. Otherwise different fractions have to be extracted by different solvents requiring additional work for sample work-up. Despite of better precision of calibration curves of SE as shown in Table S2 it must be noticed that calibration regression fittings were calculated on two different ways. The standard addition as used for IDTD for calculation of regression curves already comprises the extraction efficiencies, whereas the calibration data of the SE method are based on derivatized standard compounds. Indeed, IDTD calibration curves for vanillic acid, acetosyringone, isopimaric acid and dehydroabietic acid showed less sensitivity compared to SE. In these cases a correction by recovery calculation is not possible due to non reliable isotope-labelled standards. PAH also showed a tendency to be underestimated in concentration when analysed by the SE method. This deviation increased with increasing boiling point of the PAH. Due to a high number of according isotope-labelled standards it is not as present as for other substances by far.

The correlation experiments showed a good consistency of the analysis methods for malic acid, mannosan, levoglucosan, phthalic acid, syringic acid and isopimaric acid, 9H-fluoren-9-one, 11H-benzo[b]fluoren-11-one and the most PAH. A good consistency for other substances was opposed by the use of internal surrogate standards which were not isotope-labelled analogues of the analytes. Dehydroabietic acid methyl ester demonstrates that this is not only a drawback of polar substances even though measured concentrations of the methyl ester were somewhat lower than those of the free acid. On the other hand derivatization yields were similar for both methods.

\section{Conclusions}

A fast in-situ derivatization thermal desorption technique was developed for GC-MS. This method is able to deal with daily ambient aerosol sampling. The feature of analysing polar compounds gets more and more important to characterize ambient aerosol supporting source apportionment studies and aerosol ageing studies, even those employing chamber experiments (Böge, 2006; Chandramouli, 2003; Edney, 2005). As an amplification of this method GCxGC-techniques (Goldstein, 2008; Ma, 2008; SchnelleKreis, 2005b) could deal with enlarged data quantities and reduces peak co-elution significantly. Although the LecoCromaTOF®-Software has a powerful deconvolution algorithm peak separation becomes a problem for chromatograms including additional silylation products. Nevertheless, one dimensional gas chromatography in combination with derivatization techniques provides more relevant information of the chemical properties of ambient aerosol than without derivatization.

A positive side effect demonstrated is the minimization of matrix effects by deactivation of active quartz fibres caused by the use of MSTFA during thermal desorption. An improvement of LOD/LOQ for PAH was shown and could also be suggested for further analytes.

The advantages of isotope-labelled standards in GC-MS are well known. They gain an even higher importance for thermal desorption methods. The response of organic compounds depends on the composition of the particle matrix and on the quartz fibres. Compared to solvent extraction not 
only a fraction of this matrix but the whole sample composition affects the analysis. This always should be kept in mind when applying thermal desorption techniques. It is strictly recommended to employ a large set of isotope-labelled standards. Even compounds like PAH and dehydroabietic methyl ester do not exhibit responses proportional to reasonable surrogates, as shown in this paper. Nevertheless, the measured concentration of these compounds may be more affected by sampling artefacts than by the analysis methods employed. We clearly demonstrated that in-situ derivatization thermal desorption gas chromatography time-of-flight mass spectrometry shows a good linearity and sensitivity over nearly one order of magnitude for analysis of the important and relatively stable biomass marker levoglucosan.

\section{Edited by: A. Kiendler-Scharr}

\section{Supplement related to this article is available online at: http://www.atmos-chem-phys.net/11/8977/2011/ acp-11-8977-2011-supplement.pdf.}

\section{References}

Bari, M. A., Baumbach, G., Kuch, B., and Scheffknecht, G.: Wood smoke as a source of particle-phase organic compounds in residential areas, Atmos. Environ., 43, 4722-4732, 2009.

Bates, M., Bruno, P., Caputi, M., Caselli, M., de Gennaro, G., and Tutino, M.: Analysis of polycyclic aromatic hydrocarbons (PAHs) in airborne particles by direct sample introduction thermal desorption GC/MS, Atmos. Environ., 42, 6144-6151, 2008.

Beiner, K., Plewka, A., Haferkorn, S., Iinuma, Y., Engewald, W., and Herrmann, H.: Quantification of organic acids in pariculate matter by coupling of thermally assisted hydrolysis and methylation with thermodesorption-gas chromatography-mass spectrometry, J. Chromatogr. A, 1216, 6642-6650, 2009.

Blau, K. and King, G. S.: Handbook of Derivatives for Chromatography, Heyden \& Son Ltd., London, UK, 1977.

Böge, O., Miao, Y., Plewka, A., and Herrmann, H.: Formation of secondary organic particle phase compounds from isoprene gasphase oxidation products: An aerosol chamber and field study, Atmos. Environ., 40, 2501-2509, 2006.

Chandramouli, B., Jang, M., and Kamens, R. M.: Gas-particle partitioning of semivolatile organic compounds (SOCs) on mixtures of aerosols in a smog chamber, Environ. Sci. Technol., 37, 41134121, 2003.

Chiappini, L., Perraudin, E., Durand-Jolibois, R., and Doussin, J.: Development of a supercritical fluid extraction-gas chromatography-mass spectrometry method for the identification of highly polar compounds in secondary organic aerosols formed from biogenic hydrocarbons in smog chamber experiments, Analyt. Bioanalyt. Chem., 386, 1749-1759, 2006.

Chow, J. C., Yu, J. Z., Watson, J. G., Hang Ho, S. S., Bohannan, T. L., Hays, M. D., and Fung, K. K.: The application of thermal methods for determining chemical composition of carbonaceous aerosols: A review, J. Environ. Sci. Health, 42, 1521-1541, 2007.
Ding, L. C., Ke, F., Wang, D. K. W., Dann, T., and Austin, C. C.: A new direct thermal desorption-GC/MS method: Organic speciation of ambient particulate matter collected in Golden, BC, Atmos. Environ., 43, 4894-4902, 2009.

Donahue, N. M., Robinson, A. L., and Pandis, S. N.: Atmospheric organic particulate matter: From smoke to secondary organic aerosol, Atmos. Environ., 43, 94-106, 2009.

Dutton, S. J., Williams, D. E., Garcia, J. K., Vedal, S., and Hannigan, M. P.: $\mathrm{PM}_{2.5}$ characterization for time series studies: Organic molecular marker speciation methods and observations from daily measurements in denver, Atmos. Environ., 43, 20082013, 2009.

Edney, E. O., Kleindienst, T. E., Conver, T. S., McIver, C. D., Corse, E. W., and Weathers, W. S.: Polar organic oxygenates in $\mathrm{PM}_{2.5}$ at a southeastern site in the United States, Atmos. Environ., 37, 3947-3965, 2003.

Edney, E. O., Kleindienst, T. E., Jaoui, M., Lewandowski, M., Offenberg, J. H., Wang, W., Claeys, M.: Formation of 2-methyl tetrols and 2-methylglyceric acid in secondary organic aerosol from laboratory irradiated isoprene/ $\mathrm{NO}_{\mathrm{x}} / \mathrm{SO}_{2}$ /air mixtures and their detection in ambient $\mathrm{PM}_{2.5}$ samples collected in the eastern United States, Atmos. Environ., 39, 5281-5289, 2005.

Fabbri, D., Prati, S., and Vassura, I.: Molecular characterisation of organic material in air fine particles $\left(\mathrm{PM}_{10}\right)$ using conventional and reactive pyrolysis-gas chromatography-mass spectrometry, J. Environ. Monitor., 4, 210-215, 2002.

Falkovich, A. H. and Rudich, Y.: Analysis of semivolatile organic compounds in atmospheric aerosols by direct sample introduction thermal desorption GC/MS, Environ. Sci. Technol., 35, 2326-2333, 2001.

Fine, P. M., Cass, G. R., and Simoneit, B. R. T.: Chemical characterization of fine particle emissions from fireplace combustion of woods grown in the northeastern United States, Environ. Sci. Technol., 35, 2665-2675, 2001.

Fine, P. M., Cass, G. R., and Simoneit, B. R. T.: Chemical characterization of fine particle emissions from the fireplace combustion of woods grown in the southern United States, Environ. Sci. Technol., 36, 1442-1451, 2002.

Fine, P. M., Cass, G. R., and Simoneit, B. R. T.: Chemical characterization of fine particle emissions from the fireplace combustion of wood types grown in the midwestern and western United States, Environ. Eng. Sci., 21, 387-409, 2004.

Gil-Moltó, J., Vareaa, M., Galindoa, N., and Crespo, J.: Application of an automatic thermal desorption-gas chromatographymass spectrometry system for the analysis of polycyclic aromatic hydrocarbons in airborne particulate matter, J. Chromatogr. A, 1216, 1285-1289, 2009.

Goldstein, A. H., Worton, D. R., Williams, B. J., Hering, S. V., Kreisberg, N. M., Panic, O., Gorecki, T.: Thermal desorption comprehensive two-dimensional gas chromatography for in-situ measurements of organic aerosols, J. Chromatogr. A, 1186, 340 347, 2008.

Graham, B., Mayol-Bracero, O. L., Guyon, P., Roberts, G. C., Decesari, S., Facchini, M. C., Artaxo, P., Maenhaut, W., Köll, P., and Andreae, M. O.: Water-soluble organic compounds in biomass burning aerosols over amazonia - 1. Characterization by NMR and GC-MS, J. Geophys. Res., 107, 8047, doi:10.1029/2001jd000336, 2002.

Graham, B., Guyon, P., Taylor, P. E., Artaxo, P., Maenhaut, W., 
Glovsky, M. M., Flagan, R. C., and Andreae, M. O.: Organic compounds present in the natural amazonian aerosol: Characterization by gas chromatography-mass spectrometry, J. Geophys. Res., 108, 4766, doi:10.1029/2003jd003990, 2003.

Guenther, A., Hewitt, C. N., Erickson, D., Fall, R., Geron, C., Graedel, T., Harley, P., Klinger, L., Lerdau, M., McKay, W. A., Pierce, T., Scholes, B., Steinbrecher, R., Tallamraju, R., Taylor, J., and Zimmerman, P.: A global model of natural volatile organic compound emissions, J. Geophys. Res., 100, 8873-8892, 1995.

Halket, J. M., Zaikin, V. G.: Derivatization in mass spectrometry 1. Silylation, Europ. J. Mass Spectrom., 9, 1-21, 2003.

Hallquist, M., Wenger, J. C., Baltensperger, U., Rudich, Y., Simpson, D., Claeys, M., Dommen, J., Donahue, N. M., George, C., Goldstein, A. H., Hamilton, J. F., Herrmann, H., Hoffmann, T., Iinuma, Y., Jang, M., Jenkin, M. E., Jimenez, J. L., KiendlerScharr, A., Maenhaut, W., McFiggans, G., Mentel, T. F., Monod, A., Prévôt, A. S. H., Seinfeld, J. H., Surratt, J. D., Szmigielski, R., and Wildt, J.: The formation, properties and impact of secondary organic aerosol: Current and emerging issues, Atmos. Chem. Phys., 9, 5155-5236, doi:10.5194/acp-9-5155-2009, 2009.

Hays, M. D. and Lavrich, R. J.: Developments in direct thermal extraction gas chromatography-mass spectrometry of fine aerosols, Trends Analyt. Chem., 26, 88-102, 2007.

Hays, M. D., Smith, N. D., Kinsey, J., Dong, Y., Kariher, P.: Polycyclic aromatic hydrocarbon size distributions in aerosols from appliances of residential wood combustion as determined by direct thermal desorption-GC/MS, J. Aerosol Sci., 34, 1061-1084, 2003.

Ho, S. S. H. and Yu, J. Z.: In-injection port thermal desorption and subsequent gas chromatography-mass spectrometric analysis of polycyclic aromatic hydrocarbons and n-alkanes in atmospheric aerosol samples, J. Chromatogr. A, 1059, 121-129, 2004.

Ho, S. S. H., Yua, J. Z., Chow, J. C., Zielinskaa, B., Watson, J. G., Leung Sit, E. H., and Schauer, J. J.: Evaluation of an in-injection port thermal desorption-gas chromatography/mass spectrometry method for analysis of non-polar organic compounds in ambient aerosol samples, J. Chromatogr. A, 1200, 217-227, 2008.

Kourtchev, I., Ruuskanen, T., Maenhaut, W., Kulmala, M., and Claeys, M.: Observation of 2-methyltetrols and related photo-oxidation products of isoprene in boreal forest aerosols from Hyytiälä, Finland, Atmos. Chem. Phys., 5, 2761-2770, doi:10.5194/acp-5-2761-2005, 2005.

Kuo, L.-J., Herbert, B. E., and Louchouarn, P.: Can levoglucosan be used to characterize and quantify char/charcoal black carbon in environmental media?, Org. Geochem., 39, 1466-1478, 2008.

Lambe, A. T., Chacon-Madrid, H. J., Nguyen, N. T., Weitkamp, E. A., Kreisberg, N. M., Hering, S. V., Goldstein, A. H., Donahue, N. M., and Robinson, A. L.: Organic aerosol speciation: Intercomparison of thermal desorption aerosol GC/MS (TAG) and filter-based techniques, Aerosol Sci. Technol., 44, 141-151, 2010.

Larsen III, R. K., Schantz, M. M., and Wise, S. A.: Determination of levoglucosan in particulate matter reference materials, Aerosol Sci. Technol., 40, 781-787, 2006.

Leithead, A., Li, S.-M., Hoff, R., Cheng, Y., and Brook, J.: Levoglucosan and dehydroabietic acid: Evidence of biomass burning impact on aerosol in the lower fraser valley, Atmos. Environ.,
40, 2721-2734, 2006.

Little, J. L.: Artifacts in trimethylsilyl derivatization reactions and ways to avoid them, J. Chromatogr. A, 844, 1-22, 1999.

Liu, Y., Sklorz, M., Schnelle-Kreis, J., Orasche, J., Ferge, T., Kettrup, A., and Zimmermann, R.: Oxidant denuder sampling for analysis of polycyclic aromatic hydrocarbons and their oxygenated derivates in ambient aerosol: Evaluation of sampling artefact, Chemosphere, 62, 1889-1898, 2006.

Louchouarn, P., Kuo, L.-J., Wade, T. L., and Schantz, M.: Determination of levoglucosan and its isomers in size fractions of aerosol standard reference materials, Atmos. Environ., 43, 5630-5636, 2009.

Ma, Y. and Hays, M. D.: Thermal extraction-two-dimensional gas chromatography-mass spectrometry with heart-cutting for nitrogen heterocyclics in biomass burning aerosols, J. Chromatogr. A, 1200, 228-234, 2008.

Ma, Y., Hays, M. D., Geron, C. D., Walker, J. T., and Gatari Gichuru, M. J.: Technical Note: Fast two-dimensional GC-MS with thermal extraction for anhydro-sugars in fine aerosols, Atmos. Chem. Phys., 10, 4331-4341, doi:10.5194/acp-10-43312010, 2010.

Medeiros, P. M. and Simoneit, B. R. T.: Analysis of sugars in environmental samples by gas chromatography-mass spectrometry, J. Chromatogr. A, 1141, 271-278, 2007.

Medeiros, P. M., Conte, M. H., Weber, J. C., and Simoneit, B. R. T.: Sugars as source indicators of biogenic organic carbon in aerosols collected above the howland experimental forest, maine, Atmos. Environ., 40, 1694-1705, 2006.

Nolte, C. G., Schauer, J. J., Cass, G. R., and Simoneit, B. R. T.: Highly polar organic compounds present in wood smoke and in the ambient atmosphere, Environ. Sci. Technol., 35, 1912-1919, 2001.

Nolte, C. G., Schauer, J. J., Cass, G. R., and Simoneit, B. R. T.: Trimethylsilyl derivatives of organic compounds in source samples and in atmospheric fine particulate matter, Environ. Sci. Technol., 36, 4273-4281, 2002.

Oliveira, C., Pio, C., Alves, C., Evtyugina, M., Santos, P., Gonçalves, V., Nunes, T., Silvestre, A. J. D., Palmgren, F., Wåhlin, P., and Harrad, S.: Seasonal distribution of polar organic compounds in the urban atmosphere of two large cities from the north and south of europe, Atmos. Environ., 41, 55555570, 2007.

Pashynska, V., Vermeylen, R., Vas, G., Maenhaut, W., and Claeys, M.: Development of a gas chromatographic/ion trap mass spectrometric method for the determination of levoglucosan and saccharidic compounds in atmospheric aerosols. Application to urban aerosols, J. Mass Spectrom., 37, 1249-1257, doi:10.1002/jms.391, 2002.

Schkolnik, G. and Rudich, Y.: Detection and quantification of levoglucosan in atmospheric aerosols: A review, Anal. Bioanal. Chem., 385, 26-33, 2006.

Schnelle-Kreis, J., Sklorz, M., Peters, A., Cyrys, J., Zimmermann, R.: Analysis of particle-associated semi-volatile aromatic and aliphatic hydrocarbons in urban particulate matter on a daily basis, Chemosphere, 39, 7702-7714, 2005a.

Schnelle-Kreis, J., Welthagen, W., Sklorz, M., Zimmermann, R.: Application of direct thermal desorption gas chromatography and comprehensive two-dimensional gas chromatography coupled to time of flight mass spectrometry for analysis of organic com- 
pounds in ambient aerosol particles, J. Sep. Sci., 28, 1648-1657, $2005 b$.

Schnelle-Kreis, J., Sklorz, M., Orasche, J., Stölzel, M., Peters, A., and Zimmermann, R.: Semi volatile organic compounds in ambient $\mathrm{PM}_{2.5}$. Seasonal trends and daily resolved source contributions, Environ. Sci. Technol., 41, 3821-3828, 2007.

Sheesley, R. J., DeMinter, J. T., Meiritz, M., Snyder, D. C., and Schauer, J. J.: Temporal trends in motor vehicle and secondary organic tracers using in situ methylation thermal desorption GCMS, Environ. Sci. Technol., 44, 9398-9404, 2010.

Simoneit, B. R. T., Schauer, J. J., Nolte, C. G., Oros, D. R., Elias, V. O., Fraser, M. P., Rogge, W. F., and Cass, G. R.: Levoglucosan, a tracer for cellulose in biomass burning and atmospheric particles, Atmos. Environ., 33, 173-182, 1999.

Simoneit, B. R. T., Elias, V. O., Kobayashi, M., Kawamura, K., Rushdi, A. I., Medeiros, P. M., Rogge, W. F., Didyk, Borys M. : Sugars dominant water-soluble organic compounds in soils and characterization as tracers in atmospheric particulate matter, Environ. Sci. Technol., 38, 5939-5949, 2004.

Simpson, C. D., Dills, R. L., Katz, B. S., and Kalman, D. A.: Determination of levoglucosan in atmospheric fine particulate matter, J. Air Waste Manage. Assoc., 54, 689-694, 2004.

Sklorz, M., Schnelle-Kreis, J., Liu, Y., Orasche, J., and Zimmermann, R.: Daytime resolved analysis of polycyclic aromatic hydrocarbons in urban aerosol samples - impact of sources and meteorological conditions, Chemosphere, 67, 934-943, 2007.

van Drooge, B. L., Nikolova, I., and Ballesta, P. P.: Thermal desorption gas chromatography-mass spectrometry as an enhanced method for the quantification of polycyclic aromatic hydrocarbons from ambient air particulate matter, J. Chromatogr. A, 1216, 4030-4039, 2009.
Vedal, S., Hannigan, M. P., Dutton, S. J., Miller, S. L., Milford, J. B., Rabinovitch, N.,Kim, S.-Y., and Sheppard L.: The denver aerosol sources and health (dash) study: Overview and early findings, Atmos. Environ., 43, 1666-1673, 2009.

Waterman, D., Horsfield ,B., Leistner, F., Hall, K., and Smith, S.: Quantification of polycyclic aromatic hydrocarbons in the nist standard reference material (SRM1649a) urban dust using thermal desorption GC/MS, Anal. Chem., 72, 3563-3567, 2000.

Waterman, D., Horsfield, B., Hall, K., and Smith, S.: Application of micro-scale sealed vessel thermal desorption-gas chromatography-mass spectrometry for the organic analysis of airborne particulate matter: Linearity, reproducibility and quantification, J. Chromatogr. A, 912, 143-150, 2001.

Williams, B. J., Goldstein, A. H., Kreisberg, N. M., and Hering, S. V.: An in-situ instrument for speciated organic composition of atmospheric aerosols: Thermal desorption aerosol GC/MS-FID (TAG), Aerosol Sci. Technol., 40, 627-638, 2006.

Williams, B. J., Goldstein, A. H., Kreisberg, N. M., Hering, S. V., Worsnop, D. R., Ulbrich, I. M., Docherty, K. S., and Jimenez, J. L.: Major components of atmospheric organic aerosol in southern California as determined by hourly measurements of source marker compounds, Atmos. Chem. Phys., 10, 11577-11603, doi:10.5194/acp-10-11577-2010, 2010.

Zdrahal, Z., Oliveira, J., Vermeylen, R., Claeys, M., and Maenhaut, W.: Improved method for quantifying levoglucosan and related monosaccharide anhydrides in atmospheric aerosols and application to samples from urban and tropical locations, Environ. Sci Technol., 36, 747-753, 2002. 